\title{
Large-scale suspended sediment transport and sediment deposition in the Mekong Delta
}

\author{
N. V. Manh ${ }^{1}$, N. V. Dung ${ }^{1,2}$, N. N. Hung ${ }^{2}$, B. Merz ${ }^{1}$, and H. Apel ${ }^{1}$ \\ ${ }^{1}$ GFZ - German Research Center for Geoscience, Section 5.4 Hydrology, Potsdam, Germany \\ ${ }^{2}$ Southern Institute of Water Resources Research, Ho Chi Minh City, Vietnam \\ Correspondence to: N. V. Manh (manh@gfz-potsdam.de)
}

Received: 24 February 2014 - Published in Hydrol. Earth Syst. Sci. Discuss.: 17 April 2014

Revised: - - Accepted: 4 July 2014 - Published: 15 August 2014

\begin{abstract}
Sediment dynamics play a major role in the agricultural and fishery productivity of the Mekong Delta. However, the understanding of sediment dynamics in the delta, one of the most complex river deltas in the world, is very limited. This is a consequence of its large extent, the intricate system of rivers, channels and floodplains, and the scarcity of observations. This study quantifies, for the first time, the suspended sediment transport and sediment deposition in the whole Mekong Delta. To this end, a quasi-2D hydrodynamic model is combined with a cohesive sediment transport model. The combined model is calibrated using six objective functions to represent the different aspects of the hydraulic and sediment transport components. The model is calibrated for the extreme flood season in 2011 and shows good performance for 2 validation years with very different flood characteristics. It is shown how sediment transport and sediment deposition is differentiated from Kratie at the entrance of the delta on its way to the coast. The main factors influencing the spatial sediment dynamics are the river and channel system, dike rings, sluice gate operations, the magnitude of the floods, and tidal influences. The superposition of these factors leads to high spatial variability of sediment transport, in particular in the Vietnamese floodplains. Depending on the flood magnitude, annual sediment loads reaching the coast vary from 48 to $60 \%$ of the sediment load at Kratie. Deposited sediment varies from 19 to $23 \%$ of the annual load at Kratie in Cambodian floodplains, and from 1 to $6 \%$ in the compartmented and diked floodplains in Vietnam. Annual deposited nutrients (N, P, K), which are associated with the sediment deposition, provide on average more than $50 \%$ of mineral fertilizers typically applied for rice crops in non-flooded ring dike floodplains in Vietnam.
\end{abstract}

Through the quantification of sediment and related nutrient input, the presented study provides a quantitative basis for estimating the benefits of annual Mekong floods for agriculture and fishery, and is an important piece of information with regard to the assessment of the impacts of deltaic subsidence and climate-change-related sea level rise on delta morphology.

\section{Introduction}

The Mekong Delta (MD) is critical to the livelihoods and food security of millions of people in Vietnam and Cambodia. It is known as the "rice bowl" of South East Asia and one of the world's most productive fisheries. This is a result of huge floodplains and wetlands, high local flow variability and the high sediment-nutrient load of the Mekong. However, the Mekong is facing sediment starvation caused by the massive development of hydropower dams ( $\mathrm{Lu}$ and Siew, 2006; Fu and He, 2007; Fu et al., 2008; Kummu and Varis, 2007; Kummu et al., 2010; Walling, 2008; Gupta et al., 2012; Liu and He, 2012; and Liu et al., 2013). The dams planned or already under construction along the main stem of the Mekong in the middle Mekong basin might alter the sediment regime of the MD dramatically. Kummu et al. (2010) estimated that hydropower reservoirs could trap $67 \%$ of the sediment reaching the Mekong Delta compared to the status quo, if all the planned dams are built. In a more recent study, Kondolf et al. (2014) estimated that in the event that all planned dams are built, $96 \%$ of the historical sediment load of the pre-dam period would be trapped. Moreover, the MD is sinking due to human activities (Ericson et al., 2006; 
Syvitsky and Saito, 2007; Syvitsky et al., 2009; Syvitsky and Higgins, 2012). Taking into account the future reduction in sediment load of the Mekong and expected sea level rise, effective subsidence rates of $6 \mathrm{~mm} \mathrm{yr}^{-1}$ have been estimated (Syvitsky et al., 2009). Understanding and quantifying the sediment and associated nutrient transport and deposition are crucial for the economy of the MD. This knowledge would enable an estimation of the benefits of the annual floods, supplying sediment and nutrients for fisheries and a natural fertilization of the agriculturally used floodplains. It would provide a quantitative base for the ongoing debate regarding the sustainability of the increasing practice of totally blocking floodplain inundation in the Vietnamese part of the MD in favor of three cropping periods per year. Due to the lack of natural fertilization by floods, this cropping practice requires higher mineral fertilizer application (Ve, 2009). Further, it would allow for assessing the contribution of sediment deposition to counteract deltaic subsidence and climate-changerelated sea level rise.

So far, the understanding of sediment and nutrient transport and deposition in the MD is very limited. Regarding larger-scale sediment transport and deposition, only one study has been published using a combination of 1-D, 2-D and 3-D hydrodynamic models (MRCS/WUP-FIN, 2007). However, the study was limited to the Plain of Reeds (PoR, the north-eastern part of the Vietnamese MD), and it considered only the main rivers and channels. It also lacked quantitative measurement data of floodplain deposition for calibrating the model. On the plot scale, a few experimental studies targeting specific aspects exist. These include fine sediment dynamics in the Mekong estuaries (Wolanski et al., 1996), fine sediment transport and deposition in the Long Xuyen Quadrangle (Thuyen et al., 2000), sediment deposition and erosion in floodplains (Hung et al., 2014a, b), and sedimentnutrient deposition in floodplains (Vien et al., 2010; Manh et al., 2013). None of the published studies provides a quantification of the spatial distribution of sediment transport and deposition for the whole MD, although Manh et al. (2013) sampled the floodplain deposition in 11 different floodplain compartments distributed all over the northern part of the Vietnamese Mekong Delta. This study provided a first insight into the spatial variability of the floodplain deposition, but a total spatial picture could not be drawn due to the high spatial variability of the deposition and the complex channel network, both prohibiting a spatial interpolation of the results.

The heterogeneous and heavily disturbed hydraulic system of the Mekong Delta poses, in combination with the large spatial extent, a particular challenge for the quantification of sediment transport and deposition. The Vietnamese part of the MD (VMD) consists of several thousand floodplain compartments, with areas varying from approximately 50 to 500 ha. While the Cambodian floodplains show a low level of human interference, the VMD floodplains are heavily modified. Typically, a floodplain compartment is enclosed by a ring dike, which is surrounded by channels interconnected to a ring. Hydraulic structures (sluice gates, pumps) link the floodplains to the channels. The hydraulic connection between channels and floodplains in the VMD varies depending on dike level, flood magnitude and sluice gate and pump operations (Hung et al., 2012), causing a high variability in floodplain sedimentation (Manh et al., 2013).

Recently, a quasi-2D hydrodynamic model of the whole MD was developed by Dung et al. (2011) using DHI Mike 11. This model provides an appropriate compromise between model complexity, spatial coverage and resolution, and computational demand. The model includes a 1-D representation of the river and channel network and a quasi-2D representation of the VMD floodplains. The floodplains are represented as orthogonal, wide, and shallow cross sections separated from the channels by dikes and connected to the channels by control structures such as sluice gates. By applying this approach, the floodplain compartments in the VMD are represented in two dimensions but calculated in 1-D. The rather natural floodplains in Cambodia are represented with widely extended river cross sections in the 1-D model.

Given the research gaps identified above as well as previous work, this study aims at a spatially distributed modelbased quantification of the floodplain deposition in the Mekong Delta. In order to quantify the sediment transport and deposition, this study builds on the work of Dung et al. (2011) and couples the hydraulic model with a cohesive sediment transport model. The combined model is calibrated with daily water levels at 13 stations, daily discharges at 10 stations, inundation extent for several points in time, daily suspended sediment concentrations (SSC) at 2 river stations, SSC at 79 stations for 6 points in time, and annual cumulative sedimentation masses collected at 11 locations in the Vietnamese floodplains. Hence, a very comprehensive data set is used for model calibration encompassing main rivers, channels and floodplains. The model is applied to three flood events covering an extremely low flood (2010), an average flood (2009) and an extremely high flood (2011) (MRC, 2011b).

\section{Study area}

In this study the Mekong Delta is defined as the basin area downstream of the gauging station Kratie in Cambodia. This is the first gauging station upstream of Kampong Cham, where bank overtopping initiates the large floodplain inundations on the left bank of the Mekong, and the overland flood wave to the Vietnamese part of the delta (Fig. 1). Floods in the Mekong Delta are generated from the 10th-largest river discharge in the world (Gupta, 2008). The Mekong River drains an area of $795000 \mathrm{~km}^{2}$ from the eastern watershed of the Tibetan Plateau to the MD. The Mekong River has a length of about $4900 \mathrm{~km}$ and passes through China, Myanmar, Lao PDR, Thailand, Cambodia and Vietnam before 


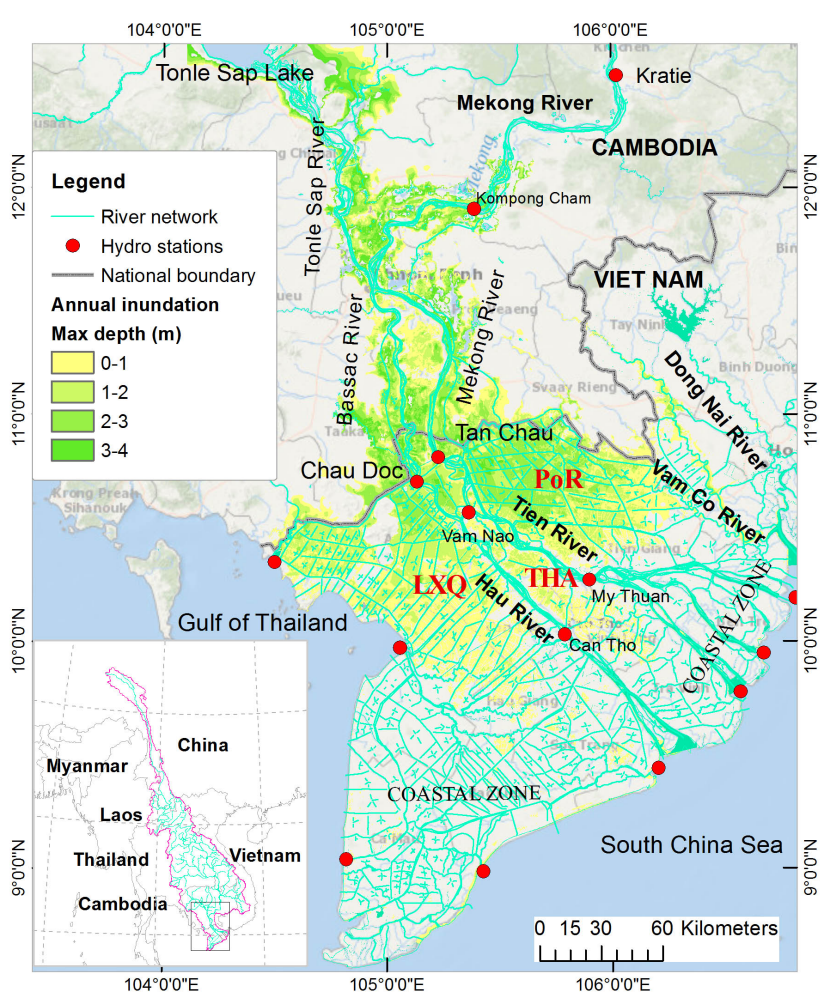

Figure 1. The Mekong Delta from Kratie to the coasts, including river network, main discharge stations and inundated area (average over 10 years).

reaching the South China Sea. The annual flood pulse in response to the western North Pacific monsoon during the months of July to October is the key hydrological characteristic of the Mekong River. The start of the flood season in the MD is defined when the mean annual discharge of $13600 \mathrm{~m}^{3} \mathrm{~s}^{-1}$ at Kratie is exceeded (MRC, 2007). The longterm average annual flood volume is $330 \mathrm{~km}^{3}$, with a mean annual flood duration of 137 days, typically starting in July (MRC, 2011a). Reported estimated annual sediment loads for the Mekong vary between 50 and 160 million tons ( $\mathrm{Lu}$ et al., 2014: 50-91 million tons; Milliman and Farnsworth, 2011: 110 million tons; Walling, 2008: 160 million tons). The annual dissolved sediment load was estimated at 60 million tons by Milliman and Farnsworth (2011).

In this work the MD is divided into the four subsystems in order to facilitate the discussion of flood hydraulics and sediment transport: (1) Cambodian Mekong Delta, (2) Tonle Sap, (3) Vietnamese Mekong Delta and (4) coastal area (Figs. 1 and 7 , right panel). In the following, the salient features of each subsystem are described.

The Cambodian Mekong Delta consists of all rivers and floodplains in Cambodia, excluding Tonle Sap. This encompasses the Mekong River downstream of Kratie until the Mekong is divided into three branches at the Chatomuk junction near Phnom Penh: the Tonle Sap River diverting water north to the Tonle Sap Lake (TSL) in Cambodia, and two branches transporting water south to the VMD and the sea, namely the Bassac River (Hau River in Vietnam) and the Mekong River (Tien River in Vietnam). These floodplains, with a total area of around $11000 \mathrm{~km}^{2}$, are in a comparative natural state, i.e., show a low level of human interference in terms of hydraulic structures and channels. During the flood season overbank flow from the Mekong and Bassac rivers causes large-scale inundations in these parts.

The Tonle Sap region includes the Tonle Sap Lake (TSL) and the Tonle Sap River. The flow into the TSL during the rising and high stage of the annual floods is reversed during the falling stage and the following dry season. Hence the TSL acts as a huge buffer retaining flood water and sediment during the flood season and increasing discharge of the Mekong during the dry season. The TSL stores up to $10 \%$ of the total wet season flow volume of Kratie, and reduces the maximum discharge measured at Kratie by $16 \%$ (MRC, 2009).

The subsystem Vietnamese Mekong Delta VMD starts at the Cambodian-Vietnamese border a few kilometers upstream of gauging stations Tan Chau and Chau Doc, and extends to My Thuan and Can Tho at the Tien River and Hau River, respectively, with an area of about $19500 \mathrm{~km}^{2}$. The VMD is a highly complex river delta as a result of anthropogenic interference, encompassing numerous channels, dikes, sluices gates and pumps. The total length of the channel network is about $91000 \mathrm{~km}$, resulting in a dike system that is approximately twice as long. An overall $75 \%$ of the $\cong 10$ million people in the VMD live in rural areas (GSO, 2012), whereas the rural residential areas are primarily distributed along the dike lines. Most of the transportation during the flood season happens on waterways, especially during high flood events. The main channels are directly connected to the Mekong and the Bassac rivers. Secondary channels distribute water from the main channels to floodplains and smaller channels. The floodplains are thus dissected into numerous, mostly rectangular compartments typically enclosed by dike rings of different heights.

The floodplains of the VMD are subdivided into three regions (Fig. 1): (1) the Long Xuyen Quadrangle (LXQ), an area of annually inundated floodplains bordering Cambodia and stretching west of the Hau River to the coast, (2) the Plains of Reeds (PoR), an area of annually inundated floodplains also bordering Cambodia but to the east of the Tien River, and (3) the area in between Tien River and Hau River (THA). The inundations in LXQ are mainly caused by the Hau River and to lesser extent by overland flow from the Cambodian floodplains. In PoR, floods are caused by the Tien River and by significant overland flow from the Cambodian floodplains providing a second flood pulse, typically with a few weeks' lag time to the peak flow of the Hau River.

Almost all floodplains in VMD are compartmented and used for agricultural production. The original floodplains are fragmented by the channel network and enclosed by ring dikes. The compartment areas range from 50 to 500 ha. They 
are linked to channels through sluice gates. The operation of these gates depends on flood magnitudes, ring dike heights and crop patterns. Ring dike systems are usually classified as low or high dike compartments. In high dike compartments the dike height is designed according to the maximum water level of the record flood in the year 2000. They are equipped with sluice gates and often with additional pumping systems. The flooding of these compartments is usually completely controlled. The total length of the high dike compartments has increased rapidly in the past 10 years. Remote sensing data show that the triple crop area, an indicator of high dike rings and complete flood control, is concentrated in LXQ and THA (Leinenkugel et al., 2013). In low dike compartments the flood can be controlled during the rising and falling stages of the flood season only. Overbank flow occurs during the high stage of the annual floods. The heights of low dike compartments vary depending on the experience and capacity of farmers. The main purpose of these dikes is the support of the farming activities. During the early stages of the flood, the dikes protect the second rice crop from flooding until it is harvested at the end of July/start of August. When the flood recedes, residual ponding water in these compartments is pumped out at the end of November, but enough water is left for planting the dry season rice crop. In years of extreme or long-lasting floods, the water volume may exceed the pumping capacity and the dry season crop is not sown, as was the case in 2011.

The coastal area subsystem covers the area downstream of My Thuan gauging station in Tien River and downstream of Can Tho station in Hau River to the sea. In this area tidal backwater effects occur throughout the year, and large-scale floodplain inundation is rare.

When considering the flood and sediment processes in the MD, the characteristics of these subsystems and of the flood wave entering the MD need to be considered. Hung et al. (2012) divided the flood season into three periods. During the rising and falling stages, the hydraulics in the MD are controlled by the river flow entering the delta at Kratie, tidal backwater effects, and flow diversion from the Mekong into TSL (rising stage) and the reverse flow from TSL to the Mekong (falling stage). The flood stage is considered high when water levels in the Mekong are high enough to counterbalance the water level of the TSL and the tidal backwater effects in the northern part of the VMD (PoR, LXQ, THA) are diminished to a large extent. In addition, the hydraulic regime and sediment dynamics in VMD are strongly influenced by human interferences, and Hung et al. (2012) found a considerable influence of crop schedules and sluice gate operation on floodplain hydraulics.

In summary, the typical flood characteristics in the MD are (1) buffering of the flood pulse by the Tonle Sap Lake, (2) a secondary flood pulse besides the river pulse caused by large-scale overbank flow over the Cambodian floodplains to the VMD, (3) large-scale, annually inundated areas $\left(>20000 \mathrm{~km}^{2}\right)$, (4) extended inundation periods
(3-4 months), and (5) strong human interference in the hydraulic regime and suspended sediment transport in the VMD.

\section{Model setup and data}

\subsection{Suspended sediment characteristics in the Mekong Delta}

The suspended sediment in the MD is fine-grained. The dispersed grain size was studied by Wolanski et al. (1996), who quantified the grain size by $d_{50}=2.5-3.9 \mu \mathrm{m}$ in the freshwater region of the estuary of the Hau River. MRC/DMS (2010) detected a $d_{50}=3-8 \mu \mathrm{m}$ in the Tonle Sap River and an even finer distribution in the Tonle Sap Lake. Manh et al. (2013) analyzed sediment deposition at 11 sites over a large area of the VMD and found that deposited sediment grain size and nutrient content are uniformly distributed over the study sites, with a dispersed grain size distribution of $41 \%$ clay (grain size $<2 \mu \mathrm{m}$ ) and $51 \%$ silt (grain size $2-63 \mu \mathrm{m}$ ). Similarly, Hung et al. (2014b) found a median grain size $d_{50}=10-15 \mu \mathrm{m}$ of deposited sediment in over 12 sediment traps on floodplains of the Plain of Reeds, VMD. The reported dispersed grain sizes of $d_{50}=2.5-15 \mu \mathrm{m}$ are equivalent to free settling velocities of $W_{0}=1 \times 10^{-5}$ $2.5 \times 10^{-4} \mathrm{~m} \mathrm{~s}^{-1}$ using Stoke's law and assuming an average measured water temperature $t \cong 30^{\circ} \mathrm{C}$, which is a representative mean value for the floodplains of the MD (Hung et al., 2014b).

However, as the sediment is cohesive (Hung et al. 2014b) the size of sediment flocs is of higher importance, particularly for the modeling. Wolanski et al. (1996) used image analysis for the measurement of flocs sizes, and observed a floc size of $d_{50} \cong 40 \mu \mathrm{m}$ of suspended sediment in the freshwater region of the estuary of the Hau River. Hung et al. (2014b) performed intensive measurements of SSC, sediment deposition, water temperature and water depth on the floodplains in the PoR and derived a floc size of $d_{50}=35 \mu \mathrm{m}$ by inverse deposition and erosion modeling. MRC/DMS (2010) measured a floc size of $d_{50} \cong 29.4 \mu \mathrm{m}$ in the Tonle Sap River using image analysis. Free settling velocities of the reported floc size in the range of $d_{50}=29.4-40 \mu \mathrm{m}$ are equivalent to $W_{0}=9 \times 10^{-4}-1.7 \times 10^{-3} \mathrm{~m} \mathrm{~s}^{-1}$ based on Stoke's law (Hung et al., 2014b).

Recorded maximum suspended sediment concentrations SSC in the MD are below $500 \mathrm{mg} \mathrm{L}^{-1}$. Given this maximum SSC a hindrance of sediment settling is unlikely, as it is much less than the SSC threshold for hindered sediment settling of $\mathrm{SSC}>10^{4} \mathrm{mg} \mathrm{L}^{-1}$ (Krone, 1962).

\subsection{Description of the 1-D hydrodynamic and sediment transport model}

The Mike 11 hydrodynamic model (HD) is based on one-dimensional hydrodynamic equations and solves the 
vertically integrated equations of conservation of continuity and momentum (the Saint Venant equations). The numerical solution is based on an implicit finite difference scheme developed by Abbott and Ionescu (1967).

The sediment model focuses on suspended sediment transport and deposition. The cohesive sediment transport module of Mike 11 is based on the mass conservative 1-D advectiondispersion $(\mathrm{AD})$ equation:

$$
\begin{aligned}
\frac{\delta(A \cdot \mathrm{SSC})}{\delta t} & +\frac{\delta(Q \cdot \mathrm{SSC})}{\delta x}-\frac{\delta}{\delta x}\left(A D \frac{\delta \mathrm{SSC}}{\delta x}\right) \\
& =-A \cdot K \cdot \mathrm{SSC}+C_{2} \cdot q,
\end{aligned}
$$

where SSC is the suspended sediment concentration, $D$ is the dispersion coefficient, $A$ the cross-sectional area, $K$ the linear decay coefficient, $C_{2}$ the source/sink concentration, $q$ the lateral inflow, $x$ the space coordinate and $t$ the time coordinate. The main assumptions are (1) the considered substance is completely mixed over the cross sections, implying that sources or sinks mix instantaneously over the cross section; (2) Fick's diffusion law applies, that is, the dispersive transport is proportional to the concentration gradient.

The falling velocity of sediment flocs mainly depends on sediment concentration:

$W_{\mathrm{S}}=k V C^{m}$ with $k=\frac{W_{0}(1-\mathrm{VC})^{\gamma}}{\mathrm{VC}^{m}}$,

leading to

$W_{\mathrm{S}}=W_{0}(1-\mathrm{VC})^{\gamma}$,

where $W_{\mathrm{S}}$ is the settling velocity of flocs $\left[\mathrm{m} \mathrm{s}^{-1}\right]$, $\mathrm{VC}$ the volume concentration of suspended sediment $\left[\mathrm{m}^{3} \mathrm{~m}^{-3}\right], W_{0}$ the free settling velocity, and $m, \gamma$ are empirical coefficients.

$W_{0}\left[\mathrm{~m} \mathrm{~s}^{-1}\right]$, is the free settling velocity based on Stoke's law, which is determined by the sediment grain or floc size (d):

$W_{0}=\frac{(s-1) g d^{2}}{18 \vartheta}$,

with $\vartheta=$ kinematic viscosity coefficient as a function of water temperature (for $T=30^{\circ} \mathrm{C}$ it equals $\vartheta=8.3 \times 10^{-7}$ $\left[\mathrm{m}^{2} \mathrm{~s}^{-1}\right]$ (Hung et al., 2014a)), $s=$ specific gravity of sediment particles $(s=2.65)$, and $g=$ acceleration of gravity $\left(g=9.81\left[\mathrm{~m} \mathrm{~s}^{-2}\right]\right)$.

The deposition process is described as

$S_{\mathrm{D}}=\left\{\begin{array}{ll}\frac{W_{\mathrm{S}} \operatorname{SSC}}{h_{*}}\left(1-\frac{\tau_{\mathrm{b}}}{\tau_{\mathrm{c}, \mathrm{b}}}\right) & \text { for } \tau_{\mathrm{c}, \mathrm{b}} \geq \tau_{\mathrm{b}}=\rho g \frac{V^{2}}{h^{\frac{1}{3}}\left(\frac{1}{n}\right)^{2}} \\ 0 & \text { for } \tau_{\mathrm{c}, \mathrm{b}}<\tau_{\mathrm{b}}\end{array}\right.$,

where $S_{\mathrm{D}}$ is the deposition rate $\left[\mathrm{kg} \mathrm{m}^{-3} \mathrm{~s}^{-1}\right]$ describing the source/sink term in the advection-dispersion equation. $W_{S}$ is the floc settling velocity $\left[\mathrm{m} \mathrm{s}^{-1}\right]$, SSC is suspended sediment concentration $\left[\mathrm{kg} \mathrm{m}^{-3}\right], h_{*}$ is the average depth through

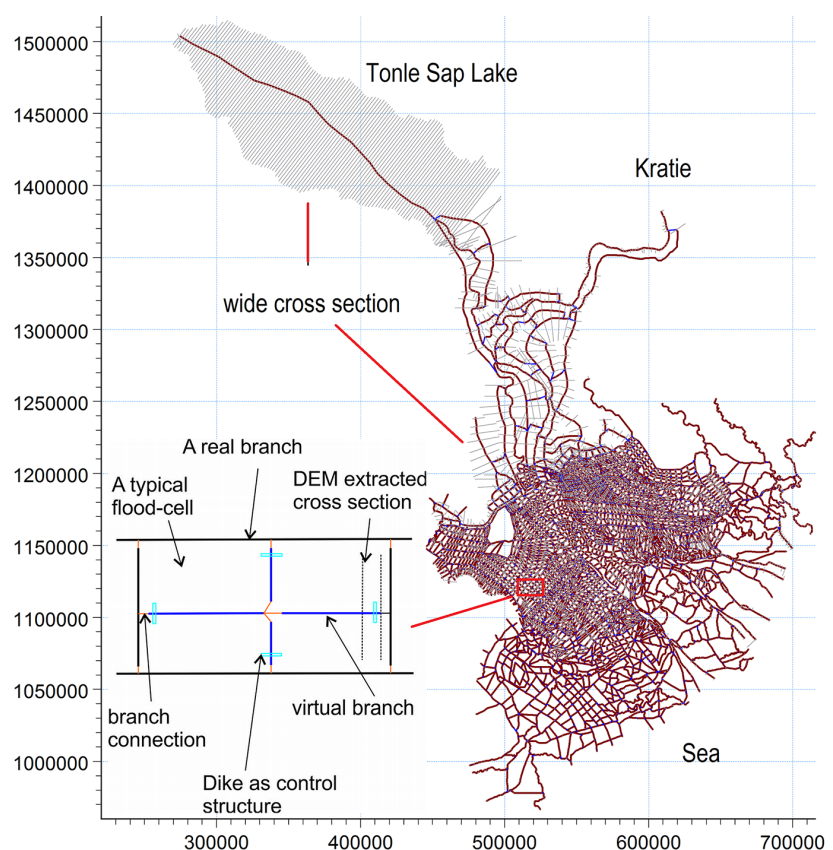

Figure 2. Model river network and quasi-2D concept for a typical floodplain compartment in the VMD.

which the particles settle $[\mathrm{m}], \tau_{\mathrm{b}}$ and $\tau_{\mathrm{c}, \mathrm{b}}$ are bed shear stress and critical bed shear stress for deposition $\left[\mathrm{Nm}^{-2}\right], \rho$ is the fluid density $\left[\mathrm{kg} \mathrm{m}^{-3}\right], g$ the acceleration of gravity $\left[\mathrm{m} \mathrm{s}^{-2}\right]$, $n$ is the Manning number, $h$ the flow depth [m] and $V$ the flow velocity $\left[\mathrm{m} \mathrm{s}^{-1}\right]$.

The gradual erosion process is described as

$S_{\mathrm{E}}=\left\{\begin{array}{ll}E_{0}\left(\frac{\tau_{\mathrm{b}}}{\tau_{\mathrm{c}, \mathrm{e}}}-1\right)^{n 1} & \text { for } \tau_{\mathrm{c}, \mathrm{e}} \leq \tau_{\mathrm{b}}=\rho g \frac{V^{2}}{h^{\frac{1}{3}}\left(\frac{1}{n}\right)^{2}} \\ 0 & \text { for } \tau_{\mathrm{c}, \mathrm{e}}>\tau_{\mathrm{b}}\end{array}\right.$,

where $S_{\mathrm{E}}$ is the rate of erosion, $E_{0}$ the erosion coefficient, $\tau_{c, \mathrm{e}}$ the critical shear stress for erosion, and $n_{1}$ is the erosion exponent.

The mass in grid point $j$ is given as

$M_{j}=\operatorname{vol}_{j} \mathrm{SSC}_{j}$,

where $M$ is the mass $[\mathrm{kg}]$ at given time at given grid point $j$, SSC is suspended sediment concentration $\left[\mathrm{kg} \mathrm{m}^{-3}\right]$ and vol is the volume $\left[\mathrm{m}^{3}\right]$ at grid point $j$.

\subsection{Hydrodynamic and sediment transport modeling}

The quasi-2D hydrodynamic model developed by Dung et al. (2011) is applied to simulate flood propagation and inundation in the MD from Kratie to the coast including Tonle Sap Lake. Figure 2 shows the river network of the hydrodynamic model of the $\mathrm{MD}$, and the quasi-2D representation of the floodplain compartments is illustrated. A floodplain is enclosed by main and/or secondary channels. The floodplain 
itself is represented by "virtual" channels with wide cross sections extracted from the Shuttle Radar Topography Mission (SRTM) DEM. Defining four virtual intersecting channels per compartment permits a quasi-2D simulation of the floodplain. The cross section width of each virtual channel is defined in such a way that the compartment area is preserved. Details can be found in Dung et al. (2011).

The crest levels of the dikes are modeled as sill levels of sluice gates in each floodplain compartment in the model. The width of the sluice gates in the model is either the width of sluice gates actually present for high dike compartments, or $50 \mathrm{~m}$ for low dikes modeling dike overflow. In the latter case the dike crest levels define the sill levels of the control structures in the model. Data about dikes and control structures were collected by Dung et al. (2011) from different local and regional authorities.

The calibration of Dung et al. (2011) revealed systematic errors in dike crest levels implemented in the model, probably caused by different vertical reference values of the collected dike data. Thus the model dike heights are updated based on an analysis of water masks from satellite images (Kuenzer al et., 2013) combined with maximum simulated water levels from the hydraulic model (Dung et al., 2011). The dike levels of floodplain compartments are corrected by comparing the maximum simulated water levels the with maximum observed flood extents for three flood seasons: the average flood of 2009, the exceptionally low flood of 2010 and the extreme flood 2011.

In the MD only a small number of the sluice gates have real radial or vertical gates, whereas most of the sluice gates are operated by movable high sills using sandbags. The opening time is decided by the land owner and depends on the rice crop schedule and the flood magnitude. In the model the operation of real sluice gates is controlled by the water level of the incoming flow and/or a fixed schedule. Data on the operation of these sluice gates was collected from authorities by Dung et al. (2011). The remaining artificial sluice gates modeling dikes are defined as broad-crested weirs, for which available or estimated dike levels were used to define sill levels in the model. Pumping stations are excluded in the model because the pumps are operated at the end of the flooding period only in order to drain the compartments for the new crop. In this period water levels and SSC is very low and the effects of pumping can be neglected for the estimation of floodplain deposition.

The model contains 2340 hydraulic structures consisting of weirs, culverts and sluice gates. This complexity is a challenge for the numerical stability of the cohesive sediment transport model. Hence, the model network of Dung et al. (2011) is slightly modified to satisfy stability conditions based on the Courant $\left(\mathrm{Cr}=v \frac{\Delta t}{\Delta x}<2\right)$ and Péclet number $\left(P e=v \frac{\Delta x}{D}>2\right)$. Numerical stability can be achieved by increasing the distance between the computational points $\Delta x$ to satisfy both Courant and Péclet stability criteria, and by decreasing the time step $\Delta t$ to satisfy the Courant criterion. Hence, the cross-section spacing is increased, whereby the important elements influencing the hydraulic conditions (e.g., topography, location of hydraulic structures) are taken into account. A minimum $\Delta x$ of $700 \mathrm{~m}$ and a time step $\Delta t$ of the sediment transport model of 3-5 min are chosen. This setup results in model run times of $7-12 \mathrm{~h}$ for one flood season. This model setup guarantees numerical stability of the hydrodynamic and sediment transport model and automatic model calibration is thus feasible.

The sediment dynamics in the floodplains can be strongly influenced by local resuspension due to human activities like net fishing (Manh al et., 2013). Thus measured sediment deposition in floodplains includes not only new watershed sediment from upstream but also locally eroded or redistributed sediment. However, in order to quantify the net delivery of sediments from the watershed to the delta, the disturbances from human activities are ignored in the modeling. This is achieved by setting a very high critical shear stress for erosion in the model, ensuring that no erosion occurs in the modeling. This approach is thus not aiming at a closest representation of reality, respectively the measured deposition data, which is almost impossible due to the large interference of human activities on local sedimentation processes. This study rather aims at the quantification of new annual sediment and nutrient input delivered from the Mekong Basin as well as its spatial distribution in the Mekong Delta.

\subsection{Model parameterization}

The model parameters to be defined for the HD model are the roughness coefficient $(n)$, and for the AD model the longitudinal dispersion coefficient $(D)$, the free settling velocity $\left(W_{0}\right)$ and the critical shear stress for deposition $\left(\tau_{\mathrm{d}}\right)$. In order to reduce the degrees of freedom in the parameter estimation, the MD is divided into 11 parameter zones (Table 1). Within these zones the calibration parameters are assumed to be constant. This zonation is a refinement of the zones used by Dung al et. (2011), taking into account the different characteristics of main rivers, channels and floodplains in terms of hydrodynamics and sediment transport. In order to reduce the complexity of the calibration even further, not all calibration parameters are calibrated in all 11 zones. Depending on parameter sensitivity and flow characteristics, some parameters are fixed in some zones based on region-specific literature values (Table 1).

The Manning roughness coefficient $n$ is calibrated in 10 zones. The range of $n$ in the calibration is set to 0.016 0.10 . In the coastal zone, where the flow is governed by ocean tides, $n$ is fixed to 0.016 (Chow, 1959). The longitudinal dispersion coefficient $D$ controls the dispersive sediment transport. It represents the effect of the non-uniform flow velocity distribution on suspended sediment concentration. The dispersion coefficient is determined as a function of the mean flow velocity: $D=a|V|^{b}$, with flow velocity $V$ 
Table 1. Calibration parameters and calibration zones: Manning roughness coefficient $(n)$, dispersion factor $(a)$, critical deposition shear stress $\tau_{\mathrm{c}, \mathrm{b}}\left(\mathrm{Nm}^{-2}\right)$ and free settling velocity $W_{0}\left(\mathrm{~m} \mathrm{~s}^{-1}\right)$. Least Euclidian distance Pareto-optimal parameters $(O)$ and fixed parameters $(F)$.

\begin{tabular}{lcrcll}
\hline Zone & $n$ & $a$ & $\tau_{\mathrm{c}, \mathrm{d}}$ & $W_{0}$ & Description \\
\hline 1 & $0.032 O$ & $400 F$ & $0.025 F$ & $1.3 \times 10^{-3} F$ & Mekong River: Kratie to Phnom Penh \\
2 & $0.031 O$ & $500 F$ & $0.025 F$ & $1.3 \times 10^{-3} F$ & Mekong River: Phnom Penh to border \\
3 & $0.036 O$ & $50 F$ & $0.025 F$ & $1 \times 10^{-4} O$ & Cambodian floodplains \\
4 & $0.030 O$ & $500 F$ & $0.025 F$ & $1.3 \times 10^{-3} F$ & Tien River: border to My Thuan \\
5 & $0.026 O$ & $700 F$ & $0.025 F$ & $1.3 \times 10^{-3} F$ & Tien River: My Thuan to coast \\
6 & $0.027 O$ & $500 F$ & $0.025 F$ & $1.3 \times 10^{-3} F$ & Hau River: border to Can Tho \\
7 & $0.024 O$ & $700 F$ & $0.025 F$ & $1.3 \times 10^{-3} F$ & Hau River: Can Tho to coast \\
8 & $0.034 O$ & $335 O$ & $0.021 O$ & $1 \times 10^{-4} O$ & VMD channels with $Q>100 \mathrm{~m}^{3} \mathrm{~s}^{-1}$ \\
9 & $0.025 O$ & & & & VMD channels with $Q \leq 100 \mathrm{~m}^{3} \mathrm{~s}^{-1}$ \\
10 & $0.018 O$ & $50 F$ & $0.190 O$ & $8 \times 10^{-4} O$ & VMD floodplains \\
11 & $0.016 F$ & $831 O$ & $0.025 F$ & $1.3 \times 10^{-3} F$ & Coastal zones \\
\hline
\end{tabular}

and coefficients $a, b$. Model sensitivity runs showed that the suspended sediment moving with the velocity of water (advection) is orders of magnitude higher than the spreading due to non-homogeneous velocity distribution (dispersion). Thus, to reduce the complexity of the calibration, we fix $b=1$ for the whole MD (i.e., assume a linear dependency of $D$ on $V$ ) and calibrate $a$ values for the areas with high variability of flow velocity (channels in the VMD and coastal zone, Table 1). The $a$ values in other areas are fixed based on equivalent mean flow velocities and dispersion coefficients of 81 measurements in 30 US rivers (Kashefipour and Falconer, 2002).

The selection of fixed zones for $\tau_{\mathrm{d}}$ or $W_{0}$ is based on a model sensitivity analysis. A total of 300 Monte Carlo runs were performed with the $\mathrm{AD}$ model, fixing the dispersion coefficient $D$ and $\tau_{\mathrm{d}}$ or $W_{0}$ to determine the sensitivity of $W_{0}$ and $\tau_{\mathrm{d}}$ in each zone. In zones with low sensitivities of the parameters $W_{0}$ or $\tau_{\mathrm{d}}$, this parameter was fixed (mainly the large river branches, Table 1). In zones with high sensitivities, $W_{0}$ or $\tau_{\mathrm{d}}$ were calibrated (mainly the channels in the VMD and the floodplains, Table 1). The fixed value of the free settling velocity $\left(W_{0}\right)$ was calculated using Eq. (4) based on measured sediment sizes reported in Sect. 3.1. For this we used the average floc size determined for floodplains of the Mekong Delta of $d_{50}=35 \mu \mathrm{m}$ by Hung et al. (2014b). For calibrating $W_{0}$ we used an extended range of reported dispersed and flocculated grain sizes $D_{50}=2.5-80 \mu \mathrm{m}$, which evaluates a calibration range of $W_{0}=1 \times 10^{-5}-7 \times 10^{-3} \mathrm{~m} \mathrm{~s}^{-1}$.

Furthermore, Hung et al. (2014b) estimated the deposition shear stress $\tau_{\mathrm{d}}=0.021-0.029 \mathrm{Nm}^{-2}$ for simulating sediment deposition on VMD floodplains. The median value $\tau_{\mathrm{d}}=0.025 \mathrm{Nm}^{-2}$ of that range is used for the fixed $\tau_{\mathrm{d}}$ parameters, while an extended range of $\tau_{\mathrm{d}}=0.01-0.2 \mathrm{Nm}^{-2}$ is used for the model calibration. All the fixed and optimized parameter values (result of Sect. 4) of $\tau_{\mathrm{d}}$ and $W_{0}$ for the specific zones are listed in Table 1.

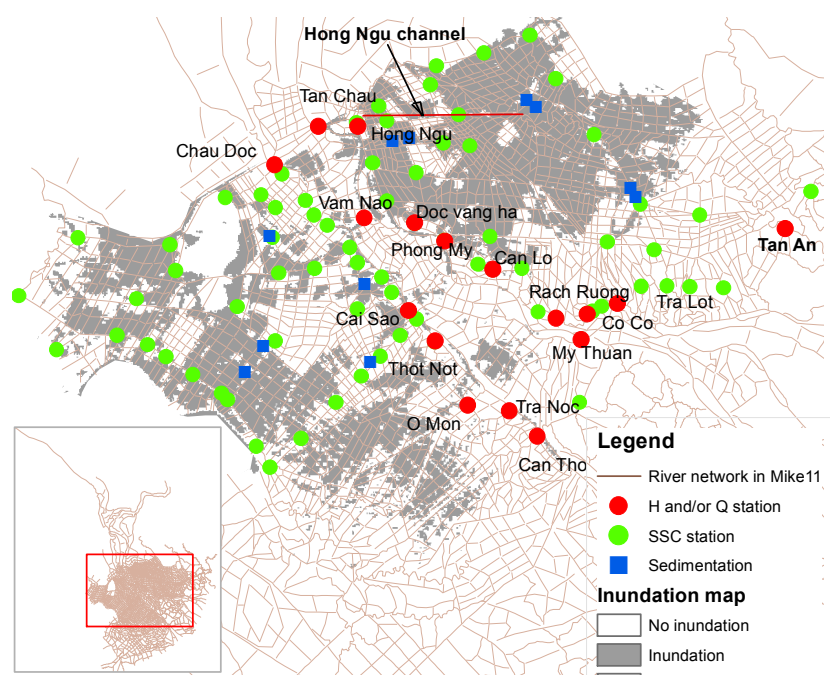

Figure 3. Locations of stations used for model calibration.

\subsection{Measurement data}

Measured data used for calibration and validation encompass water level, discharge, inundation extent, SSC in main rivers, SSC in channels, and floodplain sediment deposition (Fig. 3). The first three variables are used to calibrate the hydrodynamic module, while the latter three variables are used for sediment transport calibration. The flood in 2011 serves as calibration period, because floodplain deposition data were collected in 2011 only (Manh et al., 2013).

Daily water level and discharge data were collected for 18 stations. They include five stations in the main rivers with both discharge and water level (Tan Chau, Chau Doc, Can Tho, My Thuan, Vam Nao) and an additional seven water level stations and five discharge stations in main channels (Fig. 3). For evaluation of the spatial performance of the hydrodynamic model, water masks derived from optical MODIS satellite images are used. The simulated inundation 
extents are calibrated against these inundation maps, excluding cloud-covered areas.

For the calibration of the sediment transport, SSC data from 79 locations were acquired from the Southern Regional Hydro-Meteorological Center of Vietnam (Fig. 3). These measurements were conducted manually every 15 days during the flood period by grab water samples and suspended sediment mass quantification by filtering and drying. The sediment deposition in the compartments of the VMD of the complete flood season 2011 was monitored by Manh et al. (2013), deploying a large number of sediment traps. This study provided mean cumulative sedimentation budgets, including uncertainty ranges for 11 compartments distributed over PoR and LXQ.

In addition, Manh et al. (2013) determined the nutrient fractions of the sediment deposited in the sediment traps. Analyzed nutrients are total nitrogen (TN), total phosphorus (TP), total potassium (TK) and total organic carbon (TOC). The mass fractions of these nutrients varied only slightly in space. Thus the total nutrient content of the sediment can be estimated by an average fraction of $6.7 \%$. This value defines the total deposition of TN, TP, TK, and TOC as fractions of deposited sediment, and is used to estimate the nutrient deposition in the floodplains of the VMD. The deposition of the different nutrients is derived by the following fractions: $\mathrm{TN}=4.9 \%, \mathrm{TP}=1.9 \%, \mathrm{TK}=22.5 \%$ and $\mathrm{TOC}=70.7 \%$ of the total nutrient deposition.

\subsection{Definition of the sediment model boundary conditions}

The simulation of sediment dynamics requires specifying SSC for the upper and lower model boundary at daily resolution. However, daily SSC data are available neither for the upper model boundary nor for the lower boundary. Hence, daily SSC are reconstructed using SSC data with lower temporal resolution.

SSC time series for the lower boundaries at the river mouths were derived from remote sensing data. Water turbidity was derived from multi-sensor optical satellite scenes, and the turbidity was calibrated against in situ SSC measurements (Heege et al., 2014). This provided approximately weekly SSC values at the various river mouths. These values are linearly interpolated to daily SSC time series.

For the upper model boundary, daily SSC time series are derived from daily discharge and monthly or sporadic SSC data of the Mekong River at Kratie and neighboring gauging stations. In this analysis, however, one has to consider the reported low quality of the available SSC data (Walling et al., 2005). Before 2010 only monthly observations of water quality, including total suspended solid (TSS) at Kratie, are available. TSS was measured taking a single water sample at $0.8 \mathrm{~m}$ depth, which is a very rough and possibly strongly biased estimation of the average SSC over the whole river cross section. Recently, the Mekong River Commission (MRC) measured SSC as the average of five vertical profiles over the cross section at Kratie. The measurements were taken on 6 dates (every 2 months) in 2010 and on 20 dates from June to December 2011. The reconstruction of daily SSC at Kratie is based on this data set.

Most often SSC is reconstructed using a sediment rating curve. The 26 measurements at Kratie are significantly correlated to discharge (significance level $<0.05$ ) with a Spearman's rank correlation coefficient of $\rho=0.79$. A sediment rating curve is constructed using a second-order logarithm power function:

$\mathrm{SSC}_{t}^{\mathrm{Krat}}=10^{\left(-494.02 \log \left(Q_{t}^{\mathrm{Krat}}\right)^{-4.52}+2.88\right)}$,

in which $\mathrm{SSC}_{t}^{\mathrm{Krat}}$ is $\mathrm{SSC}\left[\mathrm{mg} \mathrm{L}^{-1}\right]$ at time $t$ at Kratie, $Q_{t}^{\mathrm{Krat}}$ is discharge $\left[\mathrm{m}^{3} \mathrm{~s}^{-1}\right]$ at time $t$ at Kratie. The rating curve is shown in Fig. 4a.

Another possibility to reconstruct SSC at Kratie is to correlate SSC at Kratie to SSC measurements at a nearby station with longer daily time series. Considering that the suspended sediment in the MD is very fine (Manh et al., 2013) and that no significant lateral SSC input downstream of Kratie exists except the flow from TSL, the measured daily SSC at Tan Chau and Chau Doc in Vietnam (see locations in Fig. 1) might be used to reconstruct daily SSC at Kratie. An analysis of the SSC data of Tan Chau and Chau Doc shows that, due to the hydraulic properties of the flow diversion of the Mekong into the Mekong, Bassac and Tonle Sap rivers, the flow into and from TSL influences mainly the SSC in the Bassac River at Chau Doc station (Fig. 4b). Hence, the daily SSC records of Tan Chau at the Mekong River are used as a predictor for SSC in Kratie. The average travel time from Kratie to Tan Chau is $1-2$ days, which is considered as lag in the correlation analysis. We found a close linear correlation $(R=0.95)$ of the measured SSC at Kratie to SSC at Tan Chau with a 1 -day lag. The linear regression is given as

$\mathrm{SSC}_{t}^{\mathrm{Krat}}=1.1 \times \mathrm{SSC}_{t+1}^{\mathrm{TC}}+12.77$,

in which $\mathrm{SSC}_{t}^{\mathrm{Krat}}$ is $\mathrm{SSC}\left[\mathrm{mg} \mathrm{L}^{-1}\right]$ at time $t$ at Kratie, $\mathrm{SSC}_{t+1}^{\mathrm{TC}}$ is $\mathrm{SSC}\left[\mathrm{mg} \mathrm{L}^{-1}\right]$ at time $t+1$ at Tan Chau. It is noteworthy that the same SSC measurement method is applied at both stations. Figure $4 \mathrm{~b}$ shows the regression of $\mathrm{SSC}_{t+1}^{\mathrm{TC}}$ vs. $\mathrm{SSC}_{t}^{\text {Krat }}$ along with the confidence bounds.

The derived SSC time series at Kratie based on these two methods yield very similar total sediment loads (106 million tons for the rating curve, and 107 million tons for the linear regression to Tan Chau). However, the SSC time series derived by the rating curve method is rather smooth and does not capture the SSC peaks existing in the measurements of Tan Chau. Hence, the rating curve method seems to suppress some fraction of SSC variability (Fig. 4c). Further, the regression-based method provides smaller uncertainty bounds (Fig. 4d). Based on these two arguments, the regression-based method is used to reconstruct daily SSC at the upper model boundary. 

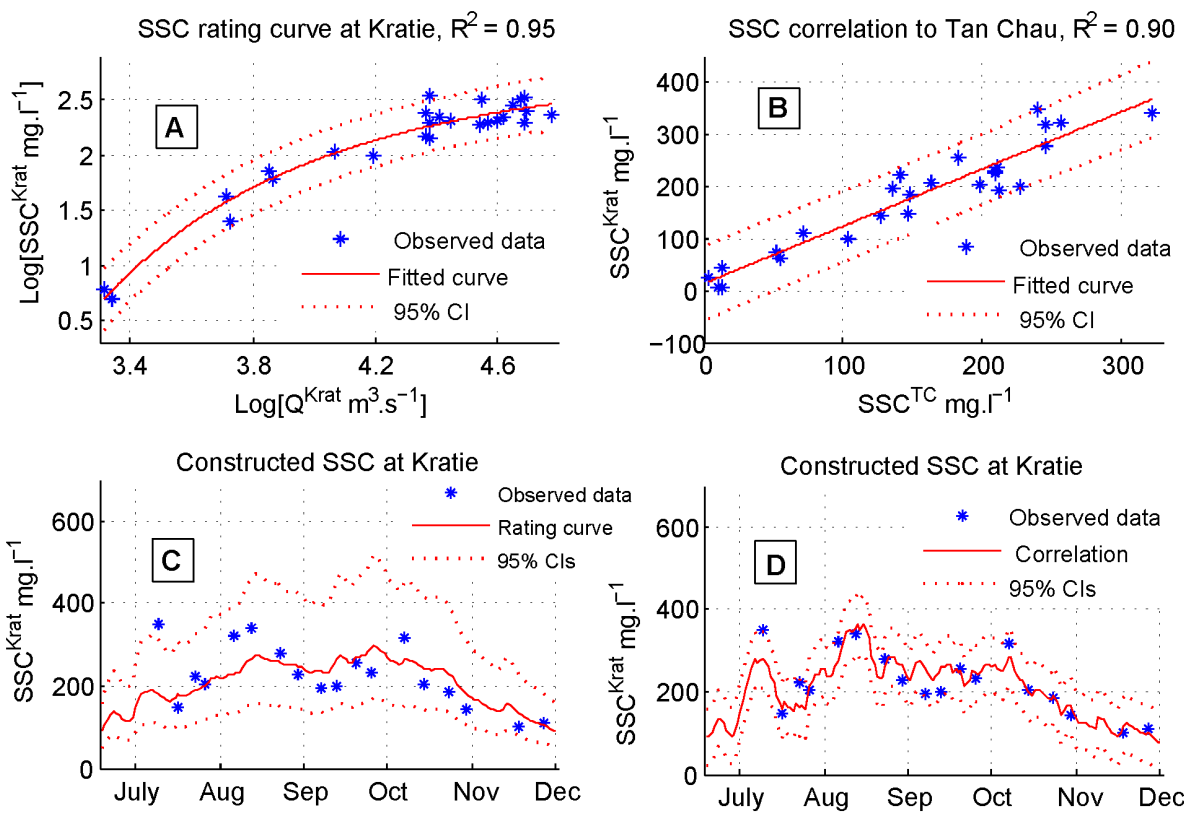

Figure 4. (a) Derived SSC for Kratie using sediment rating curve, (b) derived SSC for Kratie using correlation to SSC at Tan Chau, (c) comparison of sediment rating curve method with measured data in 2011, (d) comparison of correlation method with measured data in 2011.

\section{Model calibration and validation}

Model calibration and validation cover an extreme event (2011), a normal event (2009) and a low flood event (2010). 2011 was the most severe flood in recent times with a peak discharge in Kratie of $63 \times 10^{3} \mathrm{~s}^{-1}$, which is higher than the historically most damaging flood in 2000 . In terms of flood volume, this event is the third largest in the observation period of 88 years (MRC, 2011b). In 2010, the lowest flood volume ever was recorded. The flood peak was $37 \times 10^{3} \mathrm{~s}^{-1}$ only, and the flood lasted 6 weeks less than on average (MRC, 2011a). The year 2009 was an average flood both in terms of peak discharge and volume (MRC, 2010). The calibration is performed for the extreme flood in 2011, because for this year the most comprehensive data set, including floodplain deposition, is available. The model is validated against the data of 2009 and 2010. Hence, the model is calibrated for an extreme flood and validated against a normal flood and an extremely low flood, thus providing information about the applicability of the model over the whole possible event magnitude scale.

\subsection{Model calibration}

To reduce the complexity of the calibration and to reduce run times, the hydrodynamic (HD) and sediment transport (AD) model components are run and calibrated individually. The HD simulation results are fed as input into the AD model. This separation has the advantage that different computational time steps can be used for the two components, dramatically reducing the required runtime. The automatic multi-objective calibration algorithm developed by Dung et al. (2011) and based on the NSGA-II algorithm is applied. This enables an objective calibration considering different optimization objectives.

The HD model is calibrated with three objective functions: discharge in rivers and channels, water level in rivers and channels, and inundation extent. The first two objectives are quantified by the mean Nash-Sutcliffe efficiency (NSE) over all considered gauging stations. The spatial inundation performance is quantified by the flood area index (FAI), comparing the simulated extent with the inundation extent derived from MODIS Terra images. Cloud-covered areas in the MODIS images are considered as no-data in both observed and simulated inundation. This multi-objective calibration results in a Pareto-optimal set of HD model parameters. From this set we select the set with the least Euclidian distance to the optimal solution for the consequent $\mathrm{AD}$ calibration.

The AD model is calibrated with three objectives: SSC in main rivers, SSC in the channels and cumulative sedimentation rates on the floodplains. The Nash-Sutcliffe efficiency is used for the first objective, and the root mean square error (RMSE) is used for the second and third objectives. RMSE is selected because the measurements of channel SSC and sedimentation are not continuous in time. RMSE for cumulative sedimentation rate is calculated for the mean and, in addition, for the $95 \%$ confidence bounds of the observed deposition derived by Manh et al. (2013). The AD model calibration results in another Pareto-optimal parameter set, from which the parameter set with the least Euclidian distance to 

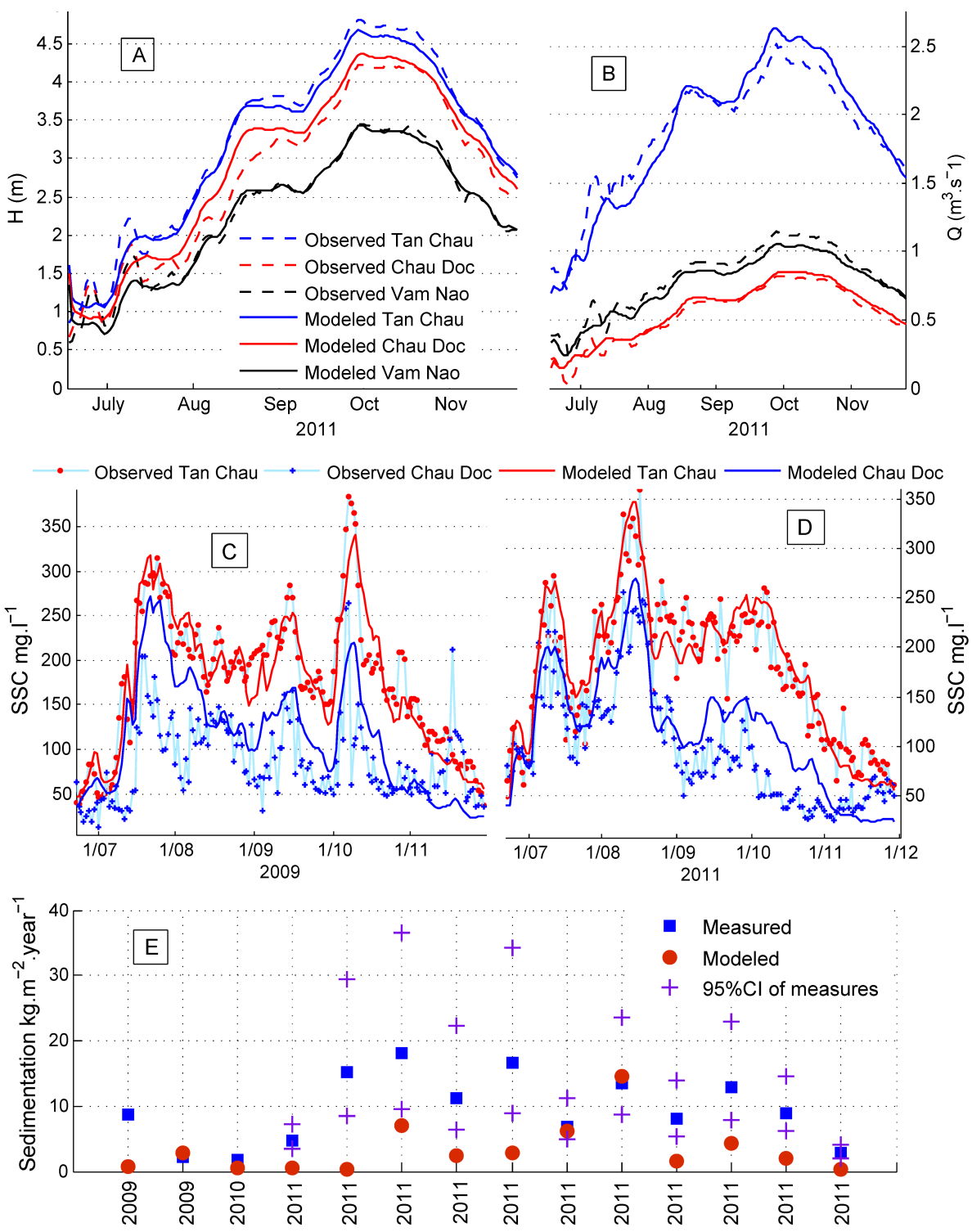

Figure 5. Model performance: top panel: comparison of measurements and simulation results at stations Tan Chau, Chau Doc and Vam Nao for 2011: (a) daily water levels, (b) daily discharges. Middle panel: comparison of measurements and simulation results at Tan Chau and Chau Doc: (d) daily SSC for the calibration year 2011, and (c) for the validation year 2009. Bottom panel: (e) comparison of measured and simulated sedimentation (2 locations in 2009, 1 location in 2010, 11 locations in 2011).

the optimal solution is again selected. The calibration zones and calibrated parameters are given in Table 1 .

\subsection{Model validation}

For model validation, the flood seasons 2009 and 2010 are used. Since floodplain sedimentation data from Manh et al. (2013) is available for 2011 only, data from Hung et al. (2013b) are used for validating sediment deposition. Hung et al. (2013b) also used sediment traps to quantify sedimentation in floodplains in 2009 (two locations) and in 2010 (one location). This data set is much less comprehensive than the data set of Manh et al. (2013), and is limited to a small study site in the PoR. Further, less data for discharge, water level and SSC is available for 2010 compared to 2011 and 2009. This needs to be considered in the interpretation of the validation results.

The calibration and validation results are summarized in Table 2 and Fig. 5a-e. Overall, the validation shows similar results as the calibration. The validation performs better for discharge and SSC in 2010, which is likely due to much less overland flow, reducing the possible errors stemming from erroneous dike levels and floodplain representation. The agreement between simulation and measurements 
Table 2. Model performance: calibration, data (locations and number of points), results of calibration (year 2011) and of validation (years 2009 and 2010). The model performance measures are Nash-Sutcliffe efficiency (NSE), flood area index (FAI), root mean square error (RMSE).

\begin{tabular}{|c|c|c|c|c|c|c|c|}
\hline \multirow[t]{2}{*}{ Objectives } & \multirow{2}{*}{$\begin{array}{l}\text { Station/ } \\
\text { point }\end{array}$} & \multicolumn{3}{|c|}{ Calibration (2011) } & \multicolumn{3}{|c|}{ Validation $(2009 / 2010)$} \\
\hline & & NSE & FAI & RMSE & NSE & FAI & RMSE \\
\hline Water level (m) & 13/daily & 0.84 & - & - & $0.74 /$ nodata & - & - \\
\hline Discharge $\left(\mathrm{m}^{3} \mathrm{~s}^{-1}\right)$ & 10/ daily & 0.63 & - & - & $0.51 / 0.74$ & - & - \\
\hline Inundation & $571 / 17$ & - & 0.46 & - & - & $0.39 / 0.36$ & - \\
\hline River SSC $\left(\mathrm{mg} \mathrm{L}^{-1}\right)$ & 2/daily & 0.52 & - & - & $0.2^{\mathrm{a}} / 0.78$ & - & - \\
\hline Channel SSC $\left(\mathrm{mg} \mathrm{L}^{-1}\right)$ & $79 / 6$ & - & - & 40 & - & - & $60 /$ nodata \\
\hline Sedimentation $\left(\mathrm{kg} \mathrm{m}^{-2} \mathrm{yr}^{-1}\right)$ & $11 /-$ & - & - & $8.55[4.4-18.8]^{\mathrm{b}}$ & - & - & $5.27 / 1.28$ \\
\hline
\end{tabular}

${ }^{\mathrm{a}}$ in which NSE $=0.9$ at Tan Chau and NSE $=-0.56$ at Chau Doc; ${ }^{\mathrm{b}}$ is the RMSE calculated against the mean $95 \%$ confidence interval of the measured deposition.

Table 3. Total sediment load, relative sediment load, flood volume (with reference to Kratie) at key locations in the MD for three flood events.

\begin{tabular}{|c|c|c|c|c|c|c|c|c|c|}
\hline \multirow[t]{2}{*}{ Subsystem } & \multicolumn{3}{|c|}{ Flood volume $(\%)$} & \multicolumn{3}{|c|}{ Sediment load (mil t) } & \multicolumn{3}{|c|}{ Sediment load (\%) } \\
\hline & 2009 & 2010 & 2011 & 2009 & 2010 & 2011 & 2009 & 2010 & 2011 \\
\hline Kratie & $100 \%$ & $100 \%$ & $100 \%$ & 78.4 & 43.4 & 104.2 & $100 \%$ & $100 \%$ & $100 \%$ \\
\hline Cam floodplains & $11 \%$ & $9 \%$ & $16 \%$ & 21.4 & 10.3 & 27.3 & $27 \%$ & $24 \%$ & $26 \%$ \\
\hline Overflow to VMD & $6 \%$ & $4 \%$ & $9 \%$ & 3.5 & 1.5 & 7 & $4 \%$ & $4 \%$ & $7 \%$ \\
\hline Tonle Sap Lake & $8 \%$ & $6 \%$ & $12 \%$ & 5.2 & 2.1 & 10.6 & $7 \%$ & $5 \%$ & $10 \%$ \\
\hline Vietnamese MD & $92 \%$ & $93 \%$ & $86 \%$ & 51.8 & 31 & 66.3 & $66 \%$ & $71 \%$ & $64 \%$ \\
\hline Tan Chau & $67 \%$ & $70 \%$ & $60 \%$ & 41 & 24.7 & 50.3 & $53 \%$ & $57 \%$ & $48 \%$ \\
\hline Chau Doc & $19 \%$ & $19 \%$ & $18 \%$ & 7.3 & 4.7 & 9 & $9 \%$ & $11 \%$ & $9 \%$ \\
\hline Vam Nao & $26 \%$ & $28 \%$ & $23 \%$ & 14.7 & 9.3 & 18.7 & $19 \%$ & $21 \%$ & $18 \%$ \\
\hline VN floodplains & $21 \%$ & $17 \%$ & $24 \%$ & 10.9 & 5.6 & 17.6 & $14 \%$ & $13 \%$ & $17 \%$ \\
\hline Coast (Sea) & - & - & - & 42 & 25.9 & 50.5 & $55 \%$ & $60 \%$ & $48 \%$ \\
\hline
\end{tabular}

for SSC at Chau Doc is very low in 2009. This is probably the consequence of the poor quality of measured data at Chau Doc station in 2009 as illustrated in Fig. 5c. Figure 5a$\mathrm{d}$ show that modeled and measured discharge and SSC fit well in 2011 for Chau Doc and in 2009 and 2011 for Tan Chau, implying coherence between SSC and discharge. This coherence is frequently not given in 2009 for Chau Doc, indicating data errors.

Overall, the model performance indices (Table 2) show a good agreement between simulation and measurements in terms of hydraulics and SSC. However, simulated sediment deposition does not match measured data as well (Fig. 5e). This is further discussed in Sect. 5.3.

\section{Results and discussion}

Table 3 shows the distribution of flood volumes into hydraulic subsystems of the MD. In the extreme event of 2011 $12 \%$ of the flood volume is distributed to the TSL and Cambodian floodplains, while during normal and low flood events $(2009,2010)$ this portion amounts to $6-8 \%$ only. The flood discharge in Tien River is about three times higher than in Hau River up to the Vam Nao junction connecting the Tien and Hau rivers. After the Vam Nao junction the discharge between the two main branches of the Mekong is almost equalized (Table 3).

The hydraulic characteristics of the sub-systems of the MD are illustrated in Fig. 6. Tidal influence is found in the entire VMD up to Tan Chau and Chau Doc, while no influence is observable at the Mekong-Bassac diversion around Phnom Penh. The tidal magnitude at Chau Doc (Hau River) is higher than at Tan Chau (Tien River) due to the lower distance to the coast. However, the situation is reversed in the coastal zone, because the semidiurnal tide of the South China Sea, mainly influencing the Tien branch, is distinctively higher than the amplitude of the diurnal tide in the Gulf of Thailand, which dampens the tidal magnitude at the river mouth of the Hau River compared to the Tien River. The flow velocity in the main river from Kratie to the Vietnamese border is almost always greater than $1 \mathrm{~m} \mathrm{~s}^{-1}$, while in the VMD channels flow velocities less than $1 \mathrm{~m} \mathrm{~s}^{-1}$ can occur, particularly during high tide. Very low flow velocities can be observed under the ponding conditions of the TSL and the floodplain compartments in VMD. Typical VMD floodplain flow velocities are in the range of $0-0.05 \mathrm{~m} \mathrm{~s}^{-1}$. The flow velocities on 

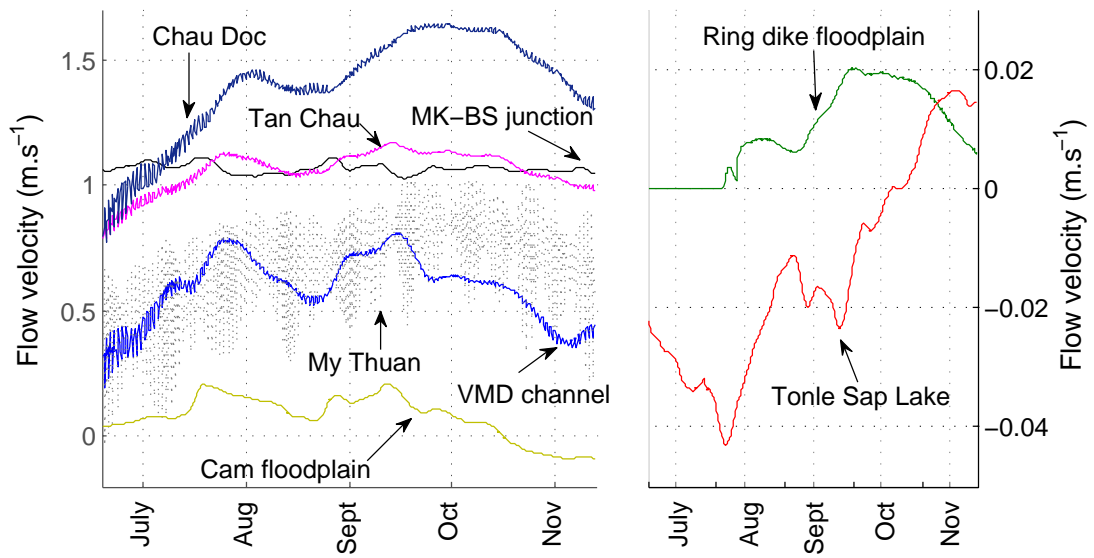

Figure 6. Flow velocity time series with $6 \mathrm{~h}$ time steps of all the sub-systems in the MD in 2009. Flow velocities of some key locations in the main rivers and in a VMD channel in the PoR (left panel, MK-BS= Mekong-Bassac), flow velocities in the center of the TSL and a floodplain compartment in the PoR (right panel).

the Cambodian floodplains vary between the river and VMD floodplain velocities, because the flow is less restricted by dikes (Fig. 6). Flow velocities in this area are thus governed by the distance to the main river and the topography. These highly differentiated flow patterns determine, in combination with the water depths, the sediment transport and deposition dynamics in the MD.

\subsection{Sediment transport in the Mekong Delta}

In the following, the results regarding SSC transport are given for the subsystems introduced in Sect. 2. The sediment fluxes of these subsystems are compared to the values at the upstream boundary Kratie. The results are summarized in Table 3, and the variation of the transported sediment from Kratie to the coast is exemplarily shown for 2009 in Fig. 7 (right panel).

Rather significant storage of water and sediment occurs in the subsystem "Tonle Sap". The flood volume stored in the TSL ranges from 6 to $12 \%$ compared to the flood volume at Kratie for the three simulated flood events. This is equivalent to $14-55 \mathrm{~km}^{3}$. These figures compare well with the average value of $41.8 \mathrm{~km}^{3}$ in the TSL water balance analysis published by Kummu et al. (2014). The total simulated sediment mass input to the TSL is $2.1 \times 10^{6} \mathrm{t}$ in $2010,5.2 \times 10^{6} \mathrm{t}$ in 2009 and $10.6 \times 10^{6} \mathrm{t}$ in 2011 (Table 3). Since the reverse flow of the TSL to the Bassac River at the end of the flood season has a low SSC, these figures are an estimate of the total sediment loss in the TSL. They compare well with the historical average value of $5.09 \times 10^{6} \mathrm{t}$ estimated by Kummu et al. (2008).

In the subsystem "Cambodian Mekong Delta", 24-27\% of the suspended sediment load of the Mekong at Kratie is transported into the Cambodian floodplains, and $4-7 \%$ is further conveyed by overland flow to PoR and LXQ in the
VMD. The remaining proportion is deposited in the Cambodian floodplains or returned to the main rivers.

The total sediment transported to the "Vietnamese Mekong Delta" varies from $64 \%$ for the extreme flood to $71 \%$ for the low flood, with a corresponding flood volume of 86 and $93 \%$, respectively. The largest fraction of the sediment is transported through the stations Tan Chau and Chau Doc, ranging from 57 to $68 \%$ (corresponding flood volume: $78-89 \%$ ) for the high and low flood year, respectively. This means the smaller the flood event, the higher the proportion of sediment load passing through Tan Chau and Chau Doc. This has to be attributed to higher sediment trapping in the TSL and the Cambodian floodplains during larger events. Furthermore, it has to be noted that the transport capacity of the Mekong River upstream of the Vam Nao junction is three to four times greater than the capacity of the Bassac River. The differentiation of SSC in the rivers from upstream to downstream is explained by sedimentation in the river bed, dispersion, and the SSC-dilution effect caused by the return flow from TSL. The TSL return flow has much lower SSC than the inflow (i.e., flow from the Mekong) due to the settlement of sediment in the TSL. As most of the TSL return flow enters the Bassac branch, SSC at Chau Doc is significantly smaller than SSC at Tan Chau during the late high and falling stage of flood events. During this period SSC at Chau Doc is approximately $50 \%$ of SSC at Kratie (Fig. $5 c-d$ ).

The transport capacity in Tien River and Hau River is balanced again through the Vam Nao junction. Around 23-28\% of the overall flood volume and $18-21 \%$ of the sediment load is conveyed from Tien River through the Vam Nao channel to Hau River. Downstream of the Vam Nao junction, Tien and Hau River carry approximately the same suspended sediment load. The total suspended sediment transport to the VMD floodplains varies from $13 \%$ for the low flood to $17 \%$ for the extreme flood. The channels in the VMD floodplains obtain 


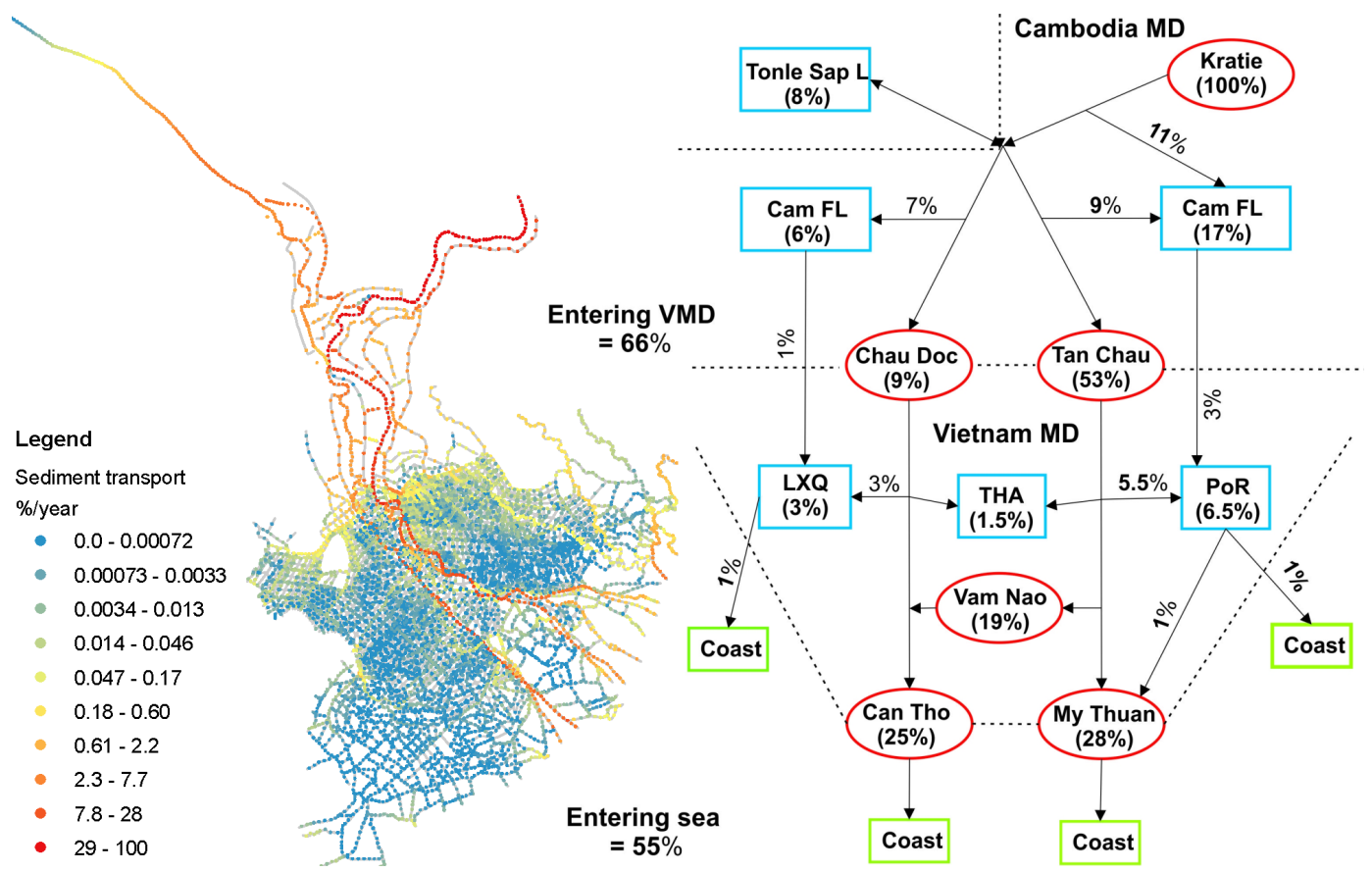

Figure 7. Proportion of transported sediment in the whole MD compared to sediment load at Kratie (left panel), and sediment load transport into subsystems (blue squares) and to key stations (red circles), both for the normal flood year 2009.

sediment from two sources: the main part stems from the Tien and Hau rivers and is conveyed through the channel network to PoR and LXQ. The second part originates from the overland flow from the Cambodian floodplains. SSC of the overland flow is lower compared to SSC in the main rivers as a consequence of the deposition on the Cambodian floodplains. The VMD floodplain compartments trap 1-6\% of the total sediment load at Kratie. This is equivalent to $9-41 \%$ of total transported sediment into the VMD floodplains.

The remaining suspended sediment is transported to the subsystem "coastal area". In the tidal backwater-influenced coastal zone, the fine sediments can also be deposited in the river beds $(9-11 \%)$. However, the model does not consider salt water intrusion or the effects of density layering on sediment deposition. Thus the simulated river bed deposition in the coastal zone can be taken as a rough indication only. Overall, the total sediment load transported to the coastal area at My Thuan and Can Tho ranges from $48 \%$ for the extreme event to $60 \%$ for the low flood.

Figure 7 (left panel) provides an overview of the spatial distribution of sediment transport in the whole MD and Fig. 7 (right panel) schematically shows the variation of the sediment load through the MD, both for the normal flood event 2009. The numbers indicate the fraction of sediment transport compared to the sediment load at Kratie. The largest proportion of sediment is kept in the main rivers and channels. As expected, the sediment loads are not equally distributed in the VMD. The highest SSC values are simulated in and close to the main Mekong branches and along the
Cambodian-Vietnamese border (PoR and LXQ), where the channels in the VMD collect the sediment of the overland flow from Cambodia. In the upper VMD the PoR receives higher sediment loads, which are also transported deeper into the floodplain area compared to LXQ. This has three reasons: (1) LXQ is directly influenced by tidal backwater effects from the Gulf of Thailand, reducing flow from the Hau River into LXQ, (2) SSC in the Hau River is generally smaller than SSC in the Tien River upstream of the Vam Nao connection, and (3) most of the floodplains with high ring dike systems blocking the inundation of the floodplains are concentrated in LXQ. In THA, the area between Tien and Hau River, almost all floodplains are fully protected by high ring dikes prohibiting floodplain inundation and deposition (if three crops are grown per year, which is the typical pattern). In the coastal areas, flow and thus sediment transport is governed by tidal influences. Most of the channels in this area do not receive significant amounts of sediment from the Tien and Hau rivers, because the prevailing alternating flow in these channels prevents a constant flow and sediment input from the main rivers into these channels.

\subsection{Sediment dynamics in the VMD floodplains}

In this section the sediment dynamics in the VMD floodplain regions PoR, LXQ and THA are elaborated. These floodplains obtain sediment from two sources: via channels connecting to Tien River and Hau River, and via channels collecting overland flow from Cambodia. 


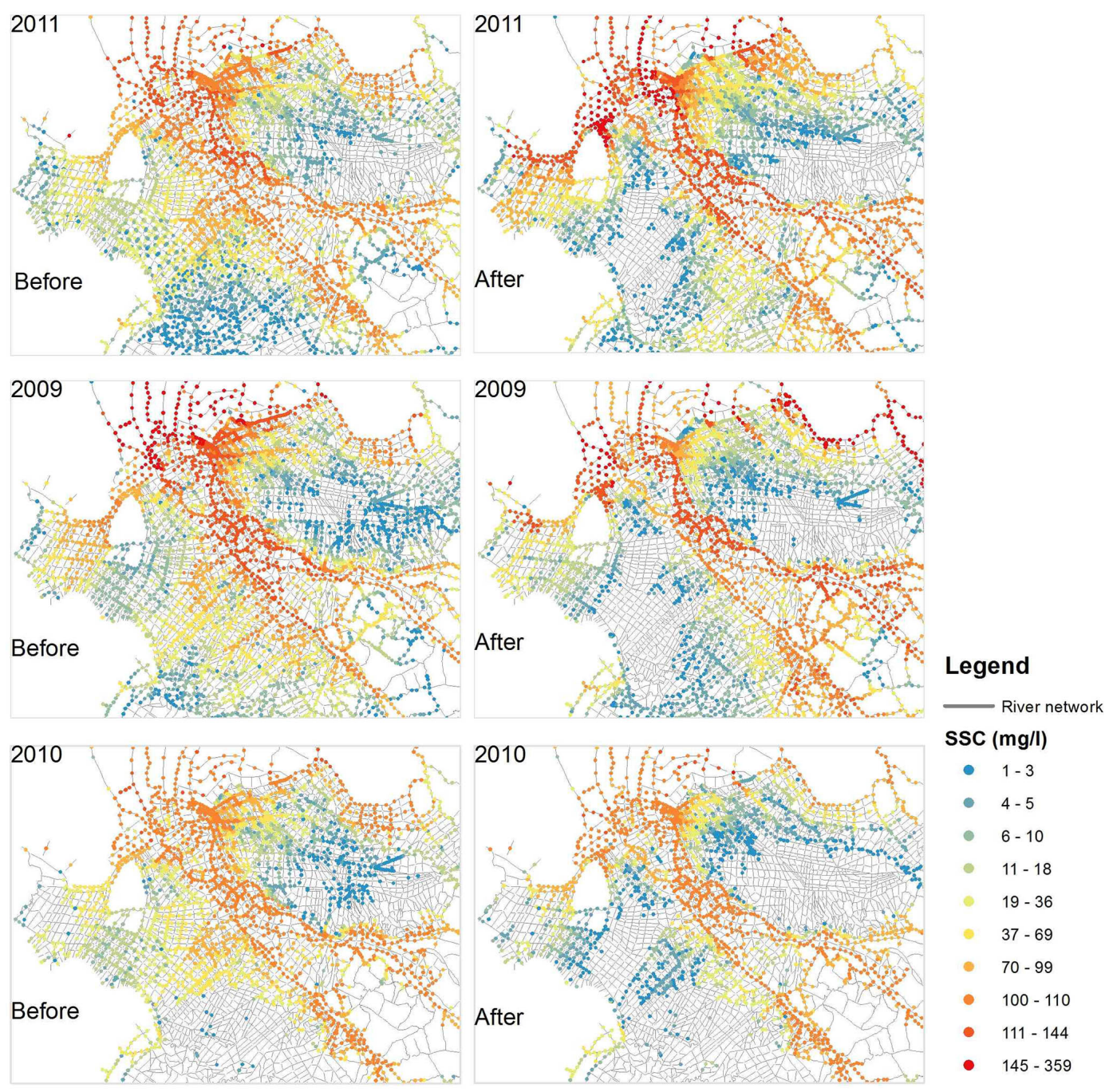

Figure 8. SSC distribution in the VMD for three floods: SSC distribution before (left panel) and after (right panel) sluice gate opening.

During the rising flood stage the bulk of the flow is concentrated in rivers and channels. Overbank flow on Cambodian floodplains does not yet occur, and flow to TSL occurs mostly through the Tonle Sap River. In the VMD, all floodplain sluice gates are still closed to protect the second rice crop of the year, but also the low dikes prevent extensive flooding of the compartments. During this phase water levels rise generally, but in the main rivers and the channel network only. SSC also rises with the onset of the flood, but SSC decreases with distance from Tien River and Hau River towards the remote parts of PoR and LXQ (see Fig. 8, left panel and Fig. 9). In both PoR and LXQ, SSC greater than $50 \mathrm{mg} \mathrm{L}^{-1}$ can be found up to a distance of $60-70 \mathrm{~km}$ from Tien River and Hau River, but also the remote parts of the floodplains show noteworthy SSCs in the channels in all simulated flood events (Fig. 8, left panel).

During the high flood stage, overbank flow occurs on both sides of the Mekong and Bassac rivers. All sluice gates in low dike compartments (as well as some of the high dike compartments, depending on the management scheme) are opened after the second rice crop harvest. Later on the low dikes are also overtopped. The VMD floodplains now receive water and sediment from Tien and Hau rivers and overland flow from the Cambodian floodplains. The SSC patterns depend on the magnitude of the overflow from the Cambodian floodplains, which has significantly smaller SSC compared to the Tien and Hau rivers. In the normal year 2009, floodplain compartments are filled through sluice gates after 23 days. This results in a drastic reduction of SSC in the channels due to sediment deposition in the compartments and in low SSC of the return flow from the compartments to the channels (Fig. 8, right panel). Notable SSC is then observed until a distance of $20 \mathrm{~km}$ from the main rivers only. SSC in the central and remote parts of the PoR and LXQ is reduced to below $5 \mathrm{mg} \mathrm{L}^{-1}$. 


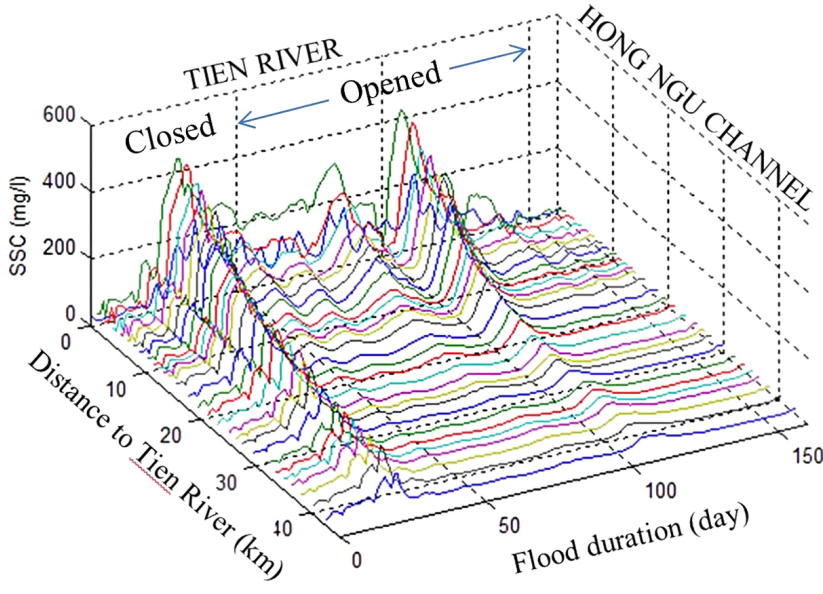

Figure 9. Typical SSC reduction in the channels with distance to the main river in the Plain of Reeds, exemplarily shown for the Hong Ngu channel in 2011.

In PoR, $24-37 \%$ of the flood volume stems from the Cambodian floodplains. Overland flow from Cambodia enters the border channels, where it is redistributed to the channels of the PoR and the Vam Co River. Flow from the Tien River also enters PoR through channels which are mainly parallel to the border channels. Due to the hydraulic head imposed by the flood water from the Cambodian floodplains, flow velocities in these channels are comparatively small. During the later period of the high flood stage, the flow into PoR from the Tien River might become stagnant or even reverse during low tide. This is, besides the compartment flooding, the reason for the low SSC in the southern part of the PoR in October, even close to the Tien River (Fig. 8, right panel). In LXQ, floodplains receive 25-33\% of the overland flood volume from the Cambodian floodplains. Like in PoR, the border channel redistributes the water to the channels of LXQ and to the Gulf of Thailand. The difference with PoR is that flood water can flow directly to the sea. The overland flood wave to LXQ is also generally lower than the overland flow to PoR. This results in a lower hydraulic head of the overland flood compared to PoR. Because in LXQ the flow from the Hau River is less dampened by the overland flood wave, higher flows and SSC rates occur in the channels of the southern parts of LXQ compared to PoR. This effect is, however, limited to regions close to the Hau River, because of the direct tidal influence of the Gulf of Thailand at the western part of the LXQ.

In the falling flood stage the flow is reverted from TSL to the Mekong just upstream of the diversion of the Bassac and Mekong branches. The return flow from TSL has low SSC, thus the SSC in the Mekong is reduced by dilution and considerably lower than during the previous flood stages with similar discharges. This SSC reduction particularly affects the Bassac River branch, where the dilution is more substantial due to incomplete transversal mixing between the confluence of the Tonle Sap River to the Mekong and the diversion of Mekong and Bassac. This effect was also highlighted by Kabeya et al. (2008) through stable isotope sampling.

The reduction of SSC with distance to the main rivers and the variation of the reduction during the flood period are illustrated in Fig. 9. It shows the simulated SSC of flood 2011 in a typical channel in the VMD, the Hong Ngu channel. It is connected to Tien River and reaches $40 \mathrm{~km}$ eastward into PoR. SSC reduction along the Hong Ngu channel (Fig. 3) differs in the different flood stages. In the rising stage, when the flow from the Tien River into the channel is not impaired by the secondary flood wave from the Cambodian floodplains and when floodplain inundation has not yet occurred in the VMD, SSC is the least reduced of all flood stages. SSC in the channel changes considerably after the opening of the sluice gates. Sediment is trapped in the compartments and the return flow dilutes SSC in the channels further. Now SSC is reduced rapidly over the first $10 \mathrm{~km}$ from the Tien River. At larger distances it remains stable at a very low level of around $20 \mathrm{~m} \mathrm{~L} \mathrm{~L}^{-1}$. This corresponds well to the SSC reduction in the same channel measured in 2008 by Hung et al. (2014a) during this flood stage.

The effect of sluice gate opening on flow dynamics in the channels is exemplarily illustrated in Fig. 10 for two nearby compartments. It shows discharge and SSC of channels upstream and downstream of two sluice gates, as well as discharge and SSC flowing in and out of the compartments. After the opening of the sluice gates, the compartments are filled within 2-3 days. After this, compartment 1 acts as a wide channel buffering the flow to the channel and to compartment 2. At the same time, suspended sediment enters the compartments and is deposited due to reduced flow velocity. The outflow from compartment 1 with very low SSC dilutes the channel SSC. The diluted flow in the channel partly enters compartment 2 , and flows further down the channel. This process is the primary reason SSC reduction in the high and falling flood stages in the VMD.

\subsection{Sedimentation and nutrient deposition in the VMD floodplains}

Floodplain sedimentation is derived from the mass balance in every simulated compartment. The annual sedimentation rate is then calculated from the gross sedimentation per year and the floodplain area. The associated nutrient deposition is estimated from the sediment deposition rate by the average total nutrient proportion of the deposited sediment of $6.7 \%$ (Manh et al., 2013). This proportion quantifies the summed deposition of total nitrogen, total phosphor, total potassium and total organic carbon. Finally, the sediment deposition depth is calculated from the cumulative sedimentation rate and the $1.2 \mathrm{t} \mathrm{m}^{-3}$ dry bulk density of sediment soil in the MD specified in Xue et al. (2010). 

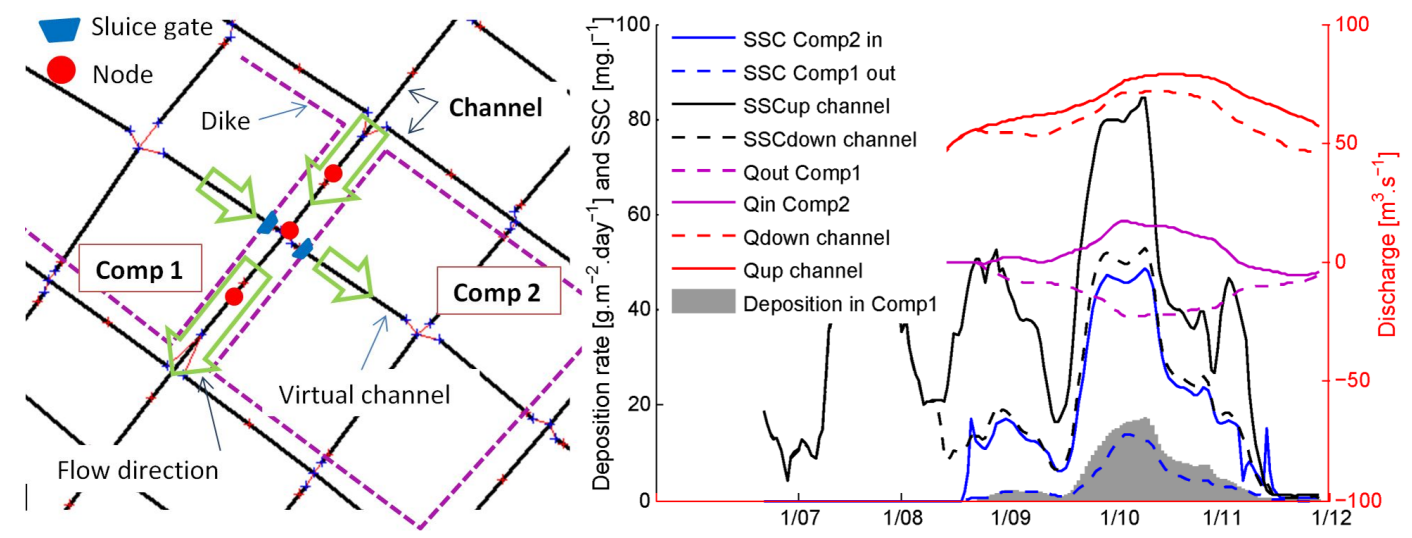

Figure 10. Flow direction in channels and two nearby compartments as represented in the hydraulic model (left panel). Discharge and sediment dynamics between the channel and two nearby compartments and sediment deposition in compartment 1 for 2011 (right panel).

A comparison of simulated sedimentation with measured data in 2011 (Manh et al., 2013) and in 2009 and 2010 (Hung et al., 2013b) is shown in Fig. 5e. A general tendency of the model to underestimate the monitored deposition can be observed. The underestimation is particularly pronounced for the high flood 2011. In 9 out of 11 locations, the simulated deposition is below the lower $95 \%$ confidence bound associated with the measurement data (Manh et al., 2013). This underestimation is likely a consequence of different reasons.

1. In the floodplains the sediment grain size is very fine and even small disturbances can cause erosion and resuspension. Hung et al. (2014b) showed that erosion can occur locally and over limited time periods in the floodplains. Also, the typical net-fishing activities on the floodplains very likely cause a considerable amount of resuspension. Furthermore, the settling velocity depends on water temperature. Hung et al. (2014b) showed by measurements that bottom-layer SSC and thus sediment settling velocity on floodplain fluctuates diurnally due to temperature changes. These effects are not described in the presented large-scale model.

2. The study focuses on the sediment delivered to the MD from the Mekong watershed. Erosion and resuspension are suppressed by the model setup using a very high critical erosion shear stress for the whole model domain. Hence erosion from bed layers and banks of channels is not simulated, and sediment input to the floodplain compartments might thus be smaller in simulation than in reality. This local erosion might be one reason for the smaller simulated sedimentation rates. However, as the SSC values in the channels are well simulated, the impact of this possible error source on the results might also be low.
3. Most of the sluice gates are operated by land owners using sandbags. The uncertainty and variability inherent in the dike levels and sluice gate operation, which is almost impossible to cover completely in the modeling, might impact the simulation of floodplain deposition. Based on field experiences and the work of Dung et al. (2011), this factor is likely to have the highest impact on the simulation results.

But despite this underestimation the simulations are valuable, because they quantify the deposition of the newly arriving sediment to the VMD, excluding local resuspension and erosion. In addition, the model enables an analysis of the spatial distribution and variability of sediment deposition over the whole MD.

Table 4 lists the cumulative sediment and nutrient deposition for the regions PoR, LXQ and THA and over the entirety of the Vietnamese floodplains. The total sediment deposition in VMD varies from 0.43 million tons in the low flood year 2010 to 6.56 million tons in the extreme flood 2011. This is equivalent to $1-6 \%$ of the total sediment load of the respective years at Kratie within the three flood events. The majority of the sediment is deposited in PoR (58-68\%), while THA receives only $8-14 \%$. The deposition in LXQ varies less and amounts to $23-28 \%$. This distribution is explained by the comparatively small floodplain area and the high number of high dike compartments in THA and LXQ.

Since the nutrient deposition is directly linked to sedimentation, the pattern of nutrient deposition is identical to the sedimentation pattern. For the extreme flood 2011, $292 \times 10^{3} \mathrm{t}, 102 \times 10^{3} \mathrm{t}$ and $45 \times 10^{3} \mathrm{t}$ of nutrients are deposited in PoR, LXQ and THA, respectively.

Table 4 also gives the spatial variability of sedimentation rates, nutrient rates and sediment depths for the three floods. This result basically depicts the effect of higher deposition in large flood events due to higher SSC, larger inundation extent and longer duration of compartment inundation. The range of sedimentation rates over the whole 
Table 4. Cumulative sediment and nutrient deposition mass in different spatial units in VMD floodplains (absolute mass and relative to Kratie), and spatial variability of sedimentation rate, deposition depths and nutrient deposition rates in the VMD.

\begin{tabular}{llllll}
\hline Zone & Item & Unit & 2009 & 2010 & 2011 \\
\hline \multirow{2}{*}{ VMD } & Sedimentation & $10^{6} \mathrm{t}$ & 2.27 & 0.43 & 6.56 \\
& & $\%$ of Kratie & $3 \%$ & $1 \%$ & $6 \%$ \\
& Nutrients & $10^{3} \mathrm{t}$ & 152.5 & 28.8 & 439.9 \\
\hline \multirow{2}{*}{ PoR } & Sedimentation & PoR/VMD & $58 \%$ & $68 \%$ & $66 \%$ \\
LXQ & and nutrients & LXQ/VMD & $28 \%$ & $23 \%$ & $23 \%$ \\
THA & & THA/VMD & $14 \%$ & $8 \%$ & $10 \%$ \\
\hline \multirow{2}{*}{ VMD } & Sedimentation & Min & 0.05 & 0.01 & 0.10 \\
& (kg m & \\
& & Mean & 1.02 & 0.36 & 2.10 \\
& Depth (Mean) & Max & 27.2 & 6.85 & 58.44 \\
& Nutrients (Mean) & $\left(\mathrm{g} \mathrm{m}^{-2}\right)$ & 0.90 & 0.30 & 1.80 \\
& & & 68.5 & 24.4 & 141.0 \\
\hline
\end{tabular}

VMD in 2011 is $0.1-58 \mathrm{~kg} \mathrm{~m}^{-2} \mathrm{yr}^{-1}$, while it is just $0.01-$ $6.8 \mathrm{~kg} \mathrm{~m}^{-2} \mathrm{yr}^{-1}$ in 2010 . These figures illustrate high temporal variability (i.e., the dependence of floodplain deposition on flood magnitude) but also very high spatial variability. This can be explained by varying distances to the main sediment sources and heterogeneous operation schedules of sluice gates. The mean deposition in THA is considerably higher than in the other regions, because the distances to main rivers and channels never exceed $10 \mathrm{~km}$ (Fig. 1). In summary, the delta-wide average sedimentation rates are $0.36,1.02$, and $2.1 \mathrm{~kg} \mathrm{~m}^{-2} \mathrm{yr}^{-1}$ in the low, normal and extreme flood, respectively, with annual mean sedimentation depths of $0.3,0.9$ and $1.8 \mathrm{~mm}$ and average nutrient deposition of 24,68 , and $141 \mathrm{~g} \mathrm{~m}^{-2} \mathrm{yr}^{-1}$. These average figures compare well to the estimated recent annual aggradation rate of $0.5 \mathrm{~mm} \mathrm{yr}^{-1}$ given for the whole Mekong Delta by Sivitski et al. (2009).

In order to quantify the benefit of nutrient deposition in inundated compartments, we compare the cumulative nutrient deposition rate with the average total amount of $\mathrm{N}, \mathrm{P}$, $\mathrm{K}$ fertilizers that is applied to rice crops in the wet season (Khuong et al., 2007). The cost of fertilizers and pesticides respectively amount to approximately 40 and $15 \%$ of the total costs per rice crop season (Thong et al., 2011; Phuong and $\mathrm{Xe}, 2011$ ). Table 5 shows the average $\mathrm{N}, \mathrm{P}, \mathrm{K}$ deposition in floodplains and the $\mathrm{N}, \mathrm{P}, \mathrm{K}$ requirements for a rice crop. Depending on the event, the floods supply $13-75 \% \mathrm{~N}, 10-58 \%$ $\mathrm{P}$, and $45-835 \% \mathrm{~K}$ to the floodplains. Under normal flood conditions (as in 2009) flooding can provide more than $50 \%$ of the typically applied rice crop fertilizers. This is a significant reduction of the costs for mineral fertilizers used in high dike compartments blocking the inundation.

Figure 11 (top row panels) shows the spatial variability of sedimentation rates in the VMD floodplains over the flood season 2009. These maps are interpolated using Kriging based on the deposition rates of the 1-D representation of the
Table 5. Nutrient requirements for a rice crop in the wet season, delta-wide mean nutrient supply from flood events to floodplains, and percentage of required nutrients supplied by flood sediments.

\begin{tabular}{llrrrrr}
\hline Event & \multicolumn{2}{l}{$\mathrm{N}\left(\mathrm{kg} \mathrm{ha}^{-1}\right)$} & \multicolumn{2}{c}{$\mathrm{P}\left(\mathrm{kg} \mathrm{ha}^{-1}\right)$} & \multicolumn{2}{c}{$\mathrm{K}\left(\mathrm{kg} \mathrm{ha}^{-1}\right)$} \\
\hline Required & 92.1 & \multicolumn{3}{c}{46.0} \\
2009 & 33.6 & $36 \%$ & 13.0 & $28 \%$ & 154.2 & $406 \%$ \\
2010 & 12.0 & $13 \%$ & 4.6 & $10 \%$ & 55.0 & $145 \%$ \\
2011 & 69.1 & $75 \%$ & 26.8 & $58 \%$ & 317.2 & $835 \%$ \\
\hline
\end{tabular}

floodplains in the hydrodynamic model. In mid-September a number of sluice gates are opened or overtopped. These are mostly located along the border of Vietnam and Cambodia, where the water levels rise first. During this period the daily sedimentation rates are quite high because of high SSC of channel water flowing into the floodplain compartments. In mid-October all the low dike compartments and some high dike compartments are overtopped or opened, in other words, a large proportion of the floodplains is inundated. The daily sedimentation rates during this peak discharge period are very high, especially in the vicinity of the Tien and Hau rivers and the border channels. In PoR almost all compartments are inundated and trap sediment, but the sedimentation rates reduce with distance from the Tien River and the border channel. Thus the deposition rate becomes quite low in the southern part of PoR. In THA most of the compartments are closed and the high dikes prevent inundation during the peak discharge. Sedimentation occurs only in some compartments along the border and close to the rivers. In these compartments the deposition rate is very high. Similarly, sediment deposition cannot occur in the central part of LXQ, where a large number of high dike compartments exist and the sluice gates remain closed during the high flood period. Like in THA, sedimentation in LXQ is mainly concentrated along the border and in close proximity of the Hau River. At the end of November the flood recedes to the upper part of the VMD and many compartments are closed to start a new crop season. Patterns of sedimentation rates are similar to those in September, but with much lower rates.

The bottom row of Fig. 11 shows maps of the annual deposition for the simulated flood events. In the extreme flood 2011, the inundated area is not much larger than during the normal flood 2009, but sedimentation rates differ strongly. Total sedimentation in 2011 is more than three times the deposition in 2009 (cf. also Table 4). This is the result of the higher flood magnitude and longer flood duration. The opposite holds true for the extremely low flood 2010: low water levels and short inundation duration allow only very low sediment deposition. The total sedimentation rate is just 19 and $6 \%$ of the total rate in the normal and extreme year, respectively. The sedimentation in the low flood year is mostly concentrated in the compartments close to the border channels and main rivers. Sediment is not deposited in central LXQ 

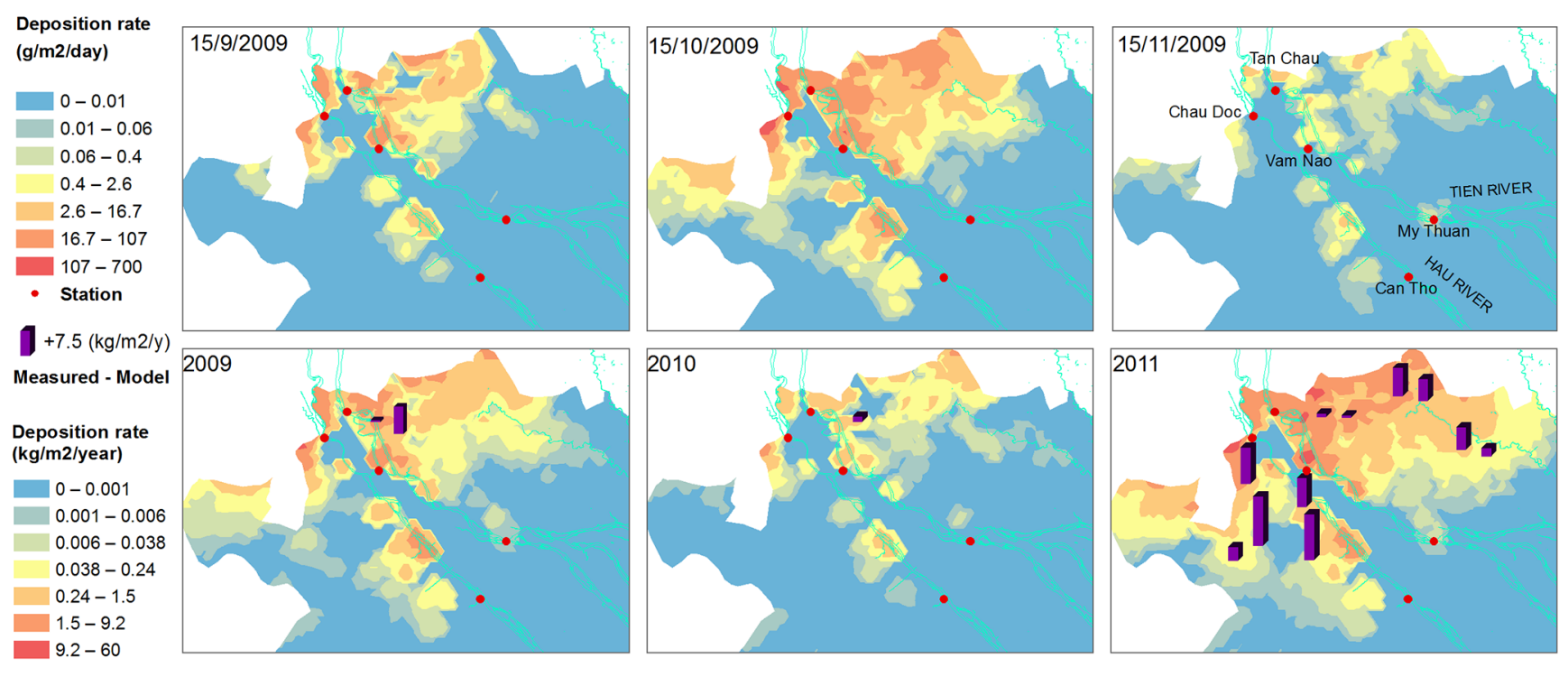

Figure 11. Map of sedimentation in the VMD floodplains. Top panels: sediment deposition rate $\left(\mathrm{g} \mathrm{m}^{-2} \mathrm{day}^{-1}\right)$ during the period of compartment opening (left panel), during flood peak discharge (center panel) and during the period of compartment closing (right panel) in the normal flood of 2009. Bottom panels: cumulative sediment deposition $\left(\mathrm{kg} \mathrm{m}^{-2} \mathrm{yr}^{-1}\right)$ in 2009, 2010 and 2011 . The bars indicate the differences between measured and simulated cumulative sediment deposition.

and very little sediment is trapped in central PoR. Figure 11 (bottom row panels) also shows the differences between measured and modeled sedimentation (vertical bars). The smallest differences are observed in upper PoR, where the sampling locations are closer to the sediment sources, i.e., Tien River and overland flow from Cambodia. In the remote areas in PoR and LXQ the simulated SSC is very small, as Figs. 8 and 9 illustrate. The main sediment source seems to be local erosion in channel beds, river banks, and floodplains, which is likely to be the major reason for the differences between measured and simulated sedimentation.

\section{Conclusions}

This study presents a comprehensive approach to quantify suspended sediment and sediment-related nutrient transport and deposition in the whole Mekong Delta. The heterogeneous system is described by a quasi-2D model linking a hydrodynamic and a cohesive sediment transport model. A twostage model calibration approach using six objective functions was applied. By this approach, different types of observed point and spatial data are taken into account with the aim to obtain the best possible model representation of the large-scale water and sediment transport. It can be concluded that, for the first time, a large-scale quantification of sediment and sediment-related nutrient transport and deposition for the whole Mekong Delta has been achieved.

The model considers only sediment originating from the Mekong Basin and entering the Mekong Delta at Kratie. Resuspension and erosion in channels and floodplains are explicitly excluded through appropriate model parameterization. As a consequence, the simulations tend to underestimate sedimentation in the floodplains. This effect is particularly pronounced in areas of the Vietnamese Mekong Delta (VMD) at a large distance from the main rivers (parts of the Plain of Reeds (PoR) and Long Xuyen Quadrangle (LXQ)). In these regions very low suspended sediment concentrations prevail, and hence erosion and remobilization is more important for floodplain sedimentation compared to regions closer to the main rivers and channels. Particularly sediment remobilization are highly influenced by human activities, specifically net fishing in channels and floodplains, but also channel bank erosion caused by ship and boat traffic is a potential local sediment source. However, the understanding and quantification of these processes require further field investigations and a more complex model setup including local erosion.

The model quantifies spatial and temporal variations of the suspended sediment transport and sediment-nutrient deposition from Kratie at the entrance of the Mekong Delta to the coast. A very high variability of floodplain sedimentation was observed in the VMD. Generally, higher rates occur in closer distances to sediment sources. During the rising flood stage no sedimentation in floodplains occurs due to closed sluice gates. The channel network is effective in transporting and distributing sediment, also deeply into remote floodplain areas. During the flood peak stage, flood water can enter floodplain compartments, initiating sediment deposition. The outflow from compartments dilutes SSC in the channels, which causes in turn a high heterogeneity of SSC in the dense channel network of the VMD. Furthermore, SSC 
becomes very small as distance from the sediment sources grows, which contributes to the very high variability of floodplain sedimentation.

Based on these findings, the following recommendations can be deduced in order to achieve higher sediment deposition and a lower spatial variability across the VMD: (1) flow of the border channels with low SSC currently entering the VMD floodplains should be redirected. This could be achieved by increasing the capacity of the border channels and directing the water to Vam Co River in PoR, or to the Gulf of Thailand in LXQ. This should cause higher SSC stemming from the Tien and Hau rivers in remote areas of the floodplains. (2) The channels starting from Tien River and Hau River should be enlarged to be able to convey higher sediment mass towards the floodplains. (3) From a management point of view, crop schedules in PoR and LXQ should be adapted to keep sluice gates open for longer periods, and compartments/sluice gates in larger distance to sediment sources should be opened earlier than the nearer compartments. Optimizing the operation of sluice gates on a larger scale is the best solution to transport and trap sediment in the floodplain compartments of PoR and LXQ in the VMD with no additional investments in infrastructure. The presented work thus supports a similar recommendation given by Hung et al. (2014a).

The presented quantification of the nutrient input by sediments presents an opportunity to assess the nutrient deficit to be expected in the high dike compartments in the VMD. It would allow a data-based cost-benefit analysis of natural inundation versus dike construction and implementation of the three-crop-per-year cropping pattern.

The study also shows, as expected, that the Mekong River basin is a net contributor of sediment to the Mekong Delta. The annual spatial average floodplain deposition of $0.3-$ $1.8 \mathrm{~mm}$, which can be much higher locally, is not only an important, but in fact the only counterbalance to land subsidence, as well as (to some extent) sea level rise in the MD (Syvitski et al., 2009). In particular, the actual and expected sea level rise exceeds floodplain deposition, and any changes leading to reduced deposition poses a serious threat to the Mekong Delta. This includes local changes in the delta like complete blocking of floodplain inundation for an increased agricultural production, but also sediment starvation of the Mekong River caused by increased damming in the Mekong Basin (Kondolf et al., 2014; Kummu et al., 2010). The most dramatic effects would be increased flood hazard and erosion, particularly of main river beds and shore lines.

The model results might also be helpful for detailed studies of this latter point by providing sediment loads entering the sea. This information can be used as boundary conditions for studies on sediment transport and erosion along the coast and the subaqueous delta. This is currently a hot topic as well, since the coastline of the Mekong Delta is subject to considerable erosion (Tamura et al., 2010; Anthony et al., 2013).
Finally, the model can be used to quantify impacts of planned and ongoing dam construction in the Mekong Basin in terms of floodplain deposition and sediment distribution in the Mekong Delta. In a similar manner, the impact of the current and expected sea level rise on the sediment transport in the MD can be estimated. These points will be covered in a follow-up study.

Acknowledgements. This work was performed within the project WISDOM - Water related Information System for a Sustainable Development of the Mekong Delta (www.wisdom.eoc.dlr.de). Funding by the German Ministry of Education and Research (BMBF) under FKZ 033L040DN and support by the Vietnamese Ministry of Science and Technology (MOST) within the framework of National project coded KC08.21/11-15 are gratefully acknowledged. We also appreciate the provision of sediment data for stations in Cambodia by Matti Kummu, Aalto University, Finland.

The service charges for this open access publication have been covered by a Research Centre of the Helmholtz Association.

Edited by: E. Todini

\section{References}

Abbott, M. and Ionescu, F.: On the numerical computation of nearly-horizontal flows, J. Hydraul. Eng., 5, 97-117, 1967.

Anthony, E. J., Goichot, M., Brunier, G., Dussouillez, P., Provansal, M., and Dolique, F.: Widespread erosion of the Mekong River Delta: from construction to destruction phase?, Mekong Environ Symp. 2013, HCM city, 2013.

Chow, V. Te: Open-channel hydraulics, McGraw-Hill, Boulder, Colorado, 728 pp., 1959.

Dung, N. V., Merz, B., Bárdossy, A., Thang, T. D., and Apel, H.: Multi-objective automatic calibration of hydrodynamic models utilizing inundation maps and gauge data, Hydrol. Earth Syst. Sci., 15, 1339-1354, doi:10.5194/hess-15-1339-2011, 2011.

Ericson, J., Vorosmarty, C., Dingman, S., Ward, L., and Meybeck, M.: Effective sea-level rise and deltas: Causes of change and human dimension implications, Global Planet. Change, 50, 63-82, doi:10.1016/j.gloplacha.2005.07.004, 2006

$\mathrm{Fu}$, K. D. and He, D. M.: Analysis and prediction of sediment trapping efficiencies of the reservoirs in the mainstream of the Lancang River, Chinese Sci. Bull., 52, 134-140, doi:10.1007/s11434-007-7026-0, 2007.

Fu, K. D., He, D. M., and Lu, X. X.: Sedimentation in the Manwan reservoir in the Upper Mekong and its downstream impacts, Quatern. Int., 186, 91-99, doi:10.1016/j.quaint.2007.09.041, 2008.

GSO: General statistic office - Statistic Yearbook of Vietnam 2012, Gen. Stat. Off. Vietnam, 150, available from: http://www.gso. gov.vn/default.aspx?tabid=512\&idmid=5\&ItemID=14153 (last access: 12 August 2014), 2012.

Gupta, A.: Large rivers: geomorphology and management, John Wiley \& Sons, Ltd, The Atrium, Southern Gate, Chichester, West Sussex, England, 2008. 
Gupta, H., Kao, S.-J., and Dai, M.: The role of mega dams in reducing sediment fluxes: A case study of large Asian rivers, J. Hydrol., 464-465, 447-458, doi:10.1016/j.jhydrol.2012.07.038, 2012.

Heege, T., Kiselev, V., Wettle, M., and Hung, N. N.: Operational multi-sensor monitoring of turbidity for the entire Mekong Delta, Int. J. Remote Sens., 35, 2910-2926, doi:10.1080/01431161.2014.890300, 2014.

Hung, N. N., Delgado, J. M., Tri, V. K., Hung, L. M., Merz, B., Bárdossy, A., and Apel, H.: Floodplain hydrology of the Mekong Delta, Vietnam, Hydrol. Process., 26, 674-686, doi:10.1002/hyp.8183, 2012.

Hung, N. N., Delgado, J. M., Güntner, A., Merz, B., Bárdossy, A., and Apel, H.: Sedimentation in the floodplains of the Mekong Delta, Vietnam. Part I: suspended sediment dynamics, Hydrol. Process., 28, 3132-3144, doi:10.1002/hyp.9856, 2014a.

Hung, N. N., Delgado, J. M., Güntner, A., Merz, B., Bárdossy, A., and Apel, H.: Sedimentation in the floodplains of the Mekong Delta, Vietnam Part II: deposition and erosion, Hydrol. Process., 28, 3145-3160, doi:10.1002/hyp.9855, 2014b.

Kabeya, N., Kubota, T., Shimizu, A., Nobuhiro, T., Tsuboyama, Y., Chann, S., and Tith, N.: Isotopic investigation of river water mixing around the confluence of the Tonle Sap and Mekong rivers, Hydrol. Process., 22, 1351-1358, 2008.

Kashefipour, S. M. and Falconer, R. A.: Longitudinal dispersion coefficients in natural channels, Water Res., 36, 1596-1608, 2002.

Khuong, T. Q., Thi, T., Huan, N., Tan, P. S., and Buresh, R.: Effect of site specific nutrient management on grain yield, nutrient use efficiency and rice production profit in the Mekong Delta, Omonrice, 158, 153-158, 2007.

Kondolf, G. M., Rubin, Z. K., and Minear, J. T.: Dams on the Mekong: Cumulative sediment starvation, Water Resour. Res., 50, 1-12, doi:10.1002/2013WR014651, 2014.

Krone, R. B.: Flume studies of the transport of sediment in estuarial shoaling process: Final report, Univ. California, Berkeley, Calif., 110 available from: http://babel.hathitrust.org/cgi/pt? id=uc1.31822020695276; view=1up;seq=9 (last access: 12 August 2014), 1962

Kuenzer, C., Guo, H., Huth, J., Leinenkugel, P., Li, X., and Dech, S.: Flood Mapping and Flood Dynamics of the Mekong Delta: ENVISAT-ASAR-WSM Based Time Series Analyses, Remote Sens., 5, 687-715, doi:10.3390/rs5020687, 2013.

Kummu, M. and Varis, O.: Sediment-related impacts due to upstream reservoir trapping, the Lower Mekong River, Geomorphology, 85, 275-293, doi:10.1016/j.geomorph.2006.03.024, 2007.

Kummu, M., Penny, D., Sarkkula, J., and Koponen, J.: Sediment: curse or blessing for Tonle Sap Lake?, Ambio, 37, 158-163, 2008.

Kummu, M., Lu, X. X., Wang, J. J., and Varis, O.: Basinwide sediment trapping efficiency of emerging reservoirs along the Mekong, Geomorphology, 119, 181-197, doi:10.1016/j.geomorph.2010.03.018, 2010.

Kummu, M., Tes, S., Yin, S., Adamson, P., Józsa, J., Koponen, J., Richey, J., and Sarkkula, J.: Water balance analysis for the Tonle Sap Lake-floodplain system, Hydrol. Process., 28, 1722-1733, doi:10.1002/hyp.9718, 2014.
Leinenkugel, P., Kuenzer, C., Oppelt, N. and Dech, S.: Characterisation of land surface phenology and land cover based on moderate resolution satellite data in cloud prone areas - A novel product for the Mekong Basin, Remote Sens. Environ., 136, 180-198, doi:10.1016/j.rse.2013.05.004, 2013.

Liu, C., He, Y., Walling, E., and Wang, J.: Changes in the sediment load of the Lancang-Mekong River over the period 1965-2003, Sci. China Technol. Sci., 56, 843-852, doi:10.1007/s11431-0135162-0, 2013.

Liu, X. and He, D.: A new assessment method for comprehensive impact of hydropower development on runoff and sediment changes, J. Geogr. Sci., 22, 1034-1044, doi:10.1007/s11442012-0981-7, 2012.

Lu, X., Kummu, M., and Oeurng, C.: Reappraisal of sediment dynamics in the Lower Mekong River, Cambodia, Earth Surf. Proc. Land., doi:10.1002/esp.3573, in press, 2014.

Lu, X. X. and Siew, R. Y.: Water discharge and sediment flux changes over the past decades in the Lower Mekong River: possible impacts of the Chinese dams, Hydrol. Earth Syst. Sci., 10, 181-195, doi:10.5194/hess-10-181-2006, 2006.

Manh, N. V., Merz, B., and Apel, H.: Sedimentation monitoring including uncertainty analysis in complex floodplains: a case study in the Mekong Delta, Hydrol. Earth Syst. Sci., 17, 3039-3057, doi:10.5194/hess-17-3039-2013, 2013.

Milliman, J. D. and Farnsworth, K. L.: River Discharge to the Coastal Ocean: A Global Synthesis, Cambridge Univ. Press, doi:10.5670/oceanog.2011.108, 2011.

MRC: Annual Mekong Flood Report 2006, Mekong River Comm., 1-94, available from: http://www. mrcmekong.org/assets/Publications/basin-reports/

Annual-Mekong-Flood-Report-2006.pdf (last access: 15 April 2014), 2007.

MRC: The Flow of the Mekong, Mekong River Comm., 1-12, available from: http://www.mrcmekong. org/assets/Publications/report-management-develop/

MRC-IM-No2-the-flow-of-the-mekong.pdf (last access: 15 April 2014), 2009.

MRC: Annual Mekong Flood Report 2009, Mekong River Comm., 1-95, available from: http://www. mrcmekong.org/assets/Publications/basin-reports/

Annual-Mekong-Flood-Report-2009.pdf (last access: 15 April 2014), 2010.

MRC: Annual Mekong Flood Report 2010, Mekong River Comm., 1-76, available from: http://www. mrcmekong.org/assets/Publications/basin-reports/ Annual-Mekong-Flood-Report-2010.pdf (last access: 15 April 2014), 2011a.

MRC: MRC Technical Paper: Flood Situation Report 2011, Mekong River Comm., 1-59, available from: http://www.mrcmekong.org/assets/Publications/technical/

Tech-No36-Flood-Situation-Report2011.pdf (last access: 15 April 2014), 2011 b.

MRC/DMS: Origin, fate and impacts of the Mekong sediments, Mekong River Comm., 53, available from: http://www.mpowernetwork.org/Knowledge_Bank/Key_ Reports/PDF/Research_Reports/DMS_Sediment_Report.pdf (last access: 15 April 2014), 2010. 
MRCS/WUP-FIN report: Research findings and recommendations, Mekong River Comm., available from: http://wacc.edu.vn/vi/ wp-content/uploads/2013/06/wup-fin2_final-reportpart2.pdf (last access: 15 April 2014), 2007.

Phuong, D. T. K. and Xe, D. Van: Assessment for efficiency finance of rice monoculture and rice - upland crops systems at Cai Lay district, Tien Giang province, J. Sci.-CTU, 18a, 220-227, 2011.

Syvitski, J. P. M. and Higgins, S.: Going under: The world's sinking deltas, New Sci., 216, 40-43, doi:10.1016/S02624079(12)63083-8, 2012.

Syvitski, J. P. M. and Saito, Y.: Morphodynamics of deltas under the influence of humans, Global Planet. Change, 57, 261-282, doi:10.1016/j.gloplacha.2006.12.001, 2007.

Syvitski, J. P. M., Kettner, A. J., Overeem, I., Hutton, E. W. H., Hannon, M. T., Brakenridge, G. R., Day, J., Vörösmarty, C., Saito, Y., Giosan, L., and Nicholls, R. J.: Sinking deltas due to human activities, Nat. Geosci., 2, 681-686, doi:10.1038/ngeo629, 2009.

Tamura, T., Horaguchi, K., Saito, Y., Nguyen, V. L., Tateishi, M., Ta, T. K. O., Nanayama, F., and Watanabe, K.: Monsooninfluenced variations in morphology and sediment of a mesotidal beach on the Mekong River delta coast, Geomorphology, 116, 11-23, doi:10.1016/j.geomorph.2009.10.003, 2010.

Thong, P. Le, Xuan, H. T. D., and Duyen, T. T. T.: Economic efficiency of Summer-Autumn and Autumn-spring rice crop in the Mekong River Delta, J. Sci.-CTU, 18a, 267-276, 2011.
Thuyen, L. X., Tran, H. N., Tuan, B. D., and Bay, N. T.: Transportation and deposition of fine sediment during flood season in Long Xuyen Quadrangle - Technical Report (Vietnamese), Minist. Sci. Technol., HCM city, Vietnam, 1-70, 2000.

Ve, N. B.: Assessment of sustainability of 3 rice crops in the Vietnamese Mekong Delta, Three rice Crop. Work., An Giang, Vietnam, 1-8, 2009.

Vien, D. M., Binh, V. V., Huong, H. T., and Guong, V. T.: Impact of sediment of Mekong river on rice yield and soil fertility, Proceedings of conference "Sustainable Agricultural Development in the Mekong Delta", Cantho University, Cantho, 1-11, 2010.

Walling, D. E.: Evaluation and analysis of sediment data from the lower Mekong River, Technical Report, available from: http://portal.mrcmekong.org/master-catalogue/ search?giai=9506000003825_00011452E0100jdi (last access: 15 April 2014), 2005.

Walling, D. E.: The changing sediment load of the Mekong River, Ambio, 37, 150-157, 2008.

Wolanski, E., Huan, N. N., Dao, L. T., Nhan, N. H., and Thuy, N. N.: Fine-sediment Dynamics in the Mekong River Estuary, Vietnam, Estuar. Coast. Shelf Sci., 43, 565-582, doi:10.1006/ecss.1996.0088, 1996.

Xue, Z., Liu, J. P., DeMaster, D., Van Nguyen, L., and Ta, T. K. O.: Late Holocene Evolution of the Mekong Subaqueous Delta, Southern Vietnam, Mar. Geol., 269, 46-60, doi:10.1016/j.margeo.2009.12.005, 2010. 